Federal Reserve Bank of New York

Staff Reports

\title{
Consumption Heterogeneity, Employment Dynamics, and Macroeconomic Co-movement
}

\author{
Stefano Eusepi \\ Bruce Preston
}

Staff Report No. 399

October 2009

Revised September 2013

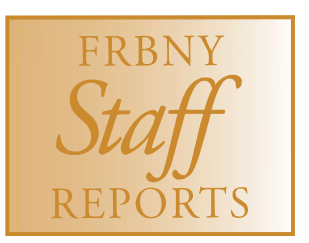

This paper presents preliminary findings and is being distributed to economists and other interested readers solely to stimulate discussion and elicit comments. The views expressed in this paper are those of the authors and are not necessarily reflective of views at the Federal Reserve Bank of New York or the Federal Reserve System. Any errors or omissions are the responsibility of the authors. 


\title{
Consumption Heterogeneity, Employment Dynamics, and Macroeconomic Co-movement Stefano Eusepi and Bruce Preston
}

Federal Reserve Bank of New York Staff Reports, no. 399

October 2009; revised September 2013

JEL classification: E13, E24, E32

\begin{abstract}
Real-business-cycle models necessarily rely on total factor productivity shocks to explain the observed co-movement between consumption, investment, and hours. However, an emerging body of evidence identifies "investment shocks" as important drivers of business cycles. This paper shows that a neoclassical model consistent with observed heterogeneity in labor supply and consumption across employed and nonemployed can generate co-movement in response to fluctuations in the marginal efficiency of investment. Estimation reveals that these shocks explain the bulk of business-cycle variance in consumption, investment, and hours. A corollary of the model's empirical success is that the labor wedge is not important at business-cycle frequencies.
\end{abstract}

Key words: business cycles, investment shocks, heterogeneity, labor market dynamics

Eusepi: Federal Reserve Bank of New York (e-mail: stefano.eusepti@ny.frb.org). Preston: Monash University (e-mail: bruce.preston@monash.edu). This is a substantially revised version of a paper distributed as "Labor Supply Heterogeneity and Macroeconomic Co-movement." The authors thank their discussants, Richard Duttu and Richard Rogerson, for detailed comments, Gianluca Violante for his help with the Consumer Expenditure Survey data, and Stefania Albanesi, Roc Armenter, Paul Beaudry, Carlos Carvalho, and Aysegul Sahin for extensive comments and discussions. They also thank seminar participants at Columbia University, the Federal Reserve Banks of Atlanta, Chicago, Philadelphia, and San Francisco, Oxford University, Cambridge University, the London School of Economics, La Trobe University, the Midwest Macroeconomics Meeting 2009, North Carolina State University, SED 2009, the Southern Workshop in Macroeconomics 2009, the European Economic Association and Econometric Society European Meeting 2009, the NBER Summer Institute 2010, the Australian Macroeconomic Workshop 2012, the University of Adelaide, the University of Melbourne, the University of British Columbia, and the Reserve Bank of New Zealand. The views expressed in this paper are those of the authors and are not necessarily reflective of views at the Federal Reserve Bank of New York or the Federal Reserve System. 


\section{Introduction}

A fundamental question in macroeconomics concerns the origins of economic fluctuations. An emerging body of evidence suggests disturbances to investment opportunities are fundamental drivers of business cycles. Fisher (2006) demonstrates innovations in the relative price of investment are central to business cycles, while Gilchrist, Ortiz, and Zakrajsek (2009) and Gilchrist and Zakrajsek (2012) adduce evidence that movements in credit spreads and, in particular, excess bond premia, have statistically and economically significant implications for economic activity in the U.S.. ${ }^{1}$ Embedding such sources of fluctuation in business-cycle models has been a challenge, a task first addressed by the seminal work of Greenwood, Hercowitz, and Huffman (1988). Indeed, standard neoclassical models of the kind proposed by Kydland and Prescott (1982) must rely on fluctuations in total factor productivity (TFP) to explain the observed co-movement between consumption, investment and hours worked — see Barro and King (1984). Intertemporal substitution of goods and leisure is the central determinant of equilibrium business cycles. Benchmark assumptions on preferences and technology, and constant TFP, predict that any change in consumption induces opposite movements in hours worked and investment. ${ }^{2}$ This presents a difficulty for many models of financial market dislocation often premised on strong intertemporal substitution motives see, for example, Carlstrom and Fuerst (1997) and Bernanke, Gertler, and Gilchrist (1999).

This paper presents a neoclassical stochastic growth model consistent with macroeconomic co-movement when faced with disturbances to the marginal efficiency of investment. Two assumptions are made, motivated by empirical evidence for the U.S., in an otherwise standard real-business-cycle model. First, as predicted by theories of time allocation — for example Becker (1965) — individual consumption expenditures are affected by the number of hours worked: the employed consume more than the non-employed in compensation for supplying labor. Aguiar and Hurst (2005) and Aguiar, Hurst, and Karabarbounis (2011) demonstrate households substitute between market and non-market work over the business cycle. And Aguiar and Hurst (2008) show that a large fraction of the drop in consumption expenditures at retirement can be explained by labor supply decisions. The resulting

\footnotetext{
${ }^{1}$ Looking at financial variables during the 2007-09 crises, movement in these spreads are shown to be connected to changes in the supply of credit.

${ }^{2}$ As noted by Campbell (1994), the standard real-business-cycle model with TFP shocks also fails to deliver co-movement if the shock is more persistent than a random walk.
} 
complementarities between consumption expenditures and hours worked are captured by non-separable preferences over these activities. Second, hours worked are adjusted for the most part on the extensive margin, which here is modeled as costly labor market participation.

Together these assumptions imply intertemporal substitution of goods and leisure induce co-movement over the business cycle through a composition effect engendered by heterogeneity in the consumption behavior of employed and non-employed workers. As an example, consider an exogenous improvement in the marginal efficiency of investment. Higher marginal value of wealth leads to higher investment, with the required resources provided by higher employment and hours worked, as well as reduced consumption of both the employed and non-employed. Despite declining individual consumption, the compositional effect arising from increased numbers of employed generates an expansion in aggregate consumption.

In a special case of our model, analytical results are provided on the parametric requirements for co-movement. Co-movement is shown to hinge on the magnitude of the consumption differential between the employed and non-employed and the relative importance of the intensive and extensive margin of labor supply. Enriching the model with variable capacity utilization and habit formation are, either individually or in combination, shown to weaken the requirements for co-movement; but are by no means necessary for our central results. In all cases heterogeneity together with hours variation on the extensive margin are necessary for co-movement. A representative-agent model with non-separability in consumption and leisure cannot generate co-movement without violating concavity of the utility function or the assumption of normality of consumption - see Bilbiie (2009). And models with heterogeneous employment decisions and separable preferences, such as Rogerson (1988), imply consumption is equalized across agents so that variations in employment do not produce composition effects on aggregate consumption.

In this context, the paper evaluates the importance of disturbances to the marginal efficiency of investment for business fluctuations in post-war U.S. data and their consequences for macroeconomic co-movement. To confront the model with data most parameters are calibrated to match evidence from microeconomic data. Focus is given to the non-separability between consumption expenditures and hours worked, which is shown to be in large part determined by the average consumption difference between employed and non-employed. 
Using evidence from available literature - Aguiar and Hurst (2005) and Aguiar and Hurst (2008) — and estimation exercises based on data from the Consumer Expenditure Survey gives an estimate of a 23 percent consumption differential. Regarding our second assumption, to capture the dominant role of employment changes in explaining fluctuations in aggregate hours it is assumed that the elasticity of individual hours worked to the real wage is one third of the elasticity of employment: this implies a volatility of employment relative to hours of roughly 80 percent, consistent with U.S. data as measured by the BLS establishment survey covering the non-farm private business sector.

The model attributes economic fluctuations to four exogenous wedges: government purchases, neutral technology, labor and investment. The wedge processes are estimated using maximum likelihood with data on total hours, consumption, output and investment. Making assumptions sufficient to identify innovations to the marginal efficiency of investment, the results reveal a substantial fraction of business-cycle variation is accounted for by these shocks - over 80 percent of variance in investment, hours and output, and roughly 50 percent of consumption - holding the other wedges constant. ${ }^{3}$ Importantly, the model generates positive co-movement between all four variables in response to an innovation in the marginal efficiency of investment. Our model provides a better fit to the data compared to both our benchmark model with separable preferences over consumption expenditures and market hours worked and also the standard real-business-cycle model. ${ }^{4}$

The role of investment shocks has been investigated using medium-sized dynamic stochastic general equilibrium models embedding nominal price and wage rigidities, together with assumptions about the conduct of monetary policy. As discussed in Justiniano, Primiceri, and Tambalotti (2011), nominal rigidities coupled with sub-optimal monetary policy can ease the co-movement problem by introducing endogenous inefficient fluctuations in price and wage mark-ups. ${ }^{5}$ However, even such richer frameworks do not offer a definitive solution. Justiniano, Primiceri, and Tambalotti (2011) demonstrate disturbances to the marginal efficiency of investment account for a large fraction of business cycles in out-

\footnotetext{
${ }^{3}$ This is a property of our identification procedure. No 'spillovers' to other wedges are permitted, in constrast to Christiano and Davis (2006).

${ }^{4}$ The benchmark model includes investment-adjustment costs, habit formation and variable capacity utilization. These model features are not required for macroeconomic comovement but do improve model fit. They are excluded in the standard real-business-cycle model.

${ }^{5}$ See also Bilbiie (2011), Furlanetto and Seneca (2010) and Hall (2011).
} 
put, investment and hours but not in consumption. This reflects the lack of conditional co-movement in response to an investment shock, despite having nominal frictions and an ad-hoc monetary policy rule. More generally, as sub-optimal monetary policy is central to resolving the co-movement problem, different assumptions about monetary policy can affect the identified role of investment shocks in business fluctuations. ${ }^{6}$

An alternative route to ensure co-movement resides in preference specifications of the kind proposed by Greenwood, Hercowitz, and Huffman (1988), which display consumptionhours complementarity and eliminate wealth effects on labor supply. Jaimovich and Rebelo (2009) delineate a modified version of GHH preferences consistent with long-term growth, making it amenable for use in commonly studied models of the business cycle. However, this preference structure implies negative wealth effects on leisure in the short-run, for which little microeconomic evidence exists. ${ }^{7}$ In addition GHH-type preferences used in the business-cycle literature imply fairly strong complementarities between consumption and hours, substantially above what is consistent with empirical evidence on the average consumption differential of employed and non-employed.

This paper focuses on a reduced-form theory of the investment wedge and does not attempt to provide microfoundations of more primitive disturbances to financial intermediation. Nonetheless, the co-movement results are quite general. Christiano, Motto, and Rostagno (2013) introduce 'risk' shocks — exogenous fluctuations to idiosyncractic uncertainty faced by entrepreneurs in creating productive capital with borrowed funds. These shocks are shown to be a better candidate of primitive disturbance, because, unlike the marginal efficiency of investment shock of Justiniano, Primiceri, and Tambalotti (2011), they generate predictions relating to asset prices that square with observed data. These shocks have, however, the same implications as shocks to the marginal efficiency of investment for the macroeconomic time series considered in this paper. Risk shocks are therefore subject to the same co-movement problems, which our framework can address. More generally, the assumptions explicated here would engender co-movement in models of uncertainty shocks proposed by Bloom (2009) and Basu and Bundick (2012); models of disaster risk such as Gourio (2011); and models of sovereign default such as Uribe and Yue (2006). Finally Eusepi

\footnotetext{
${ }^{6}$ See, for example, Gertler, Sala, and Trigari (2008).

${ }^{7}$ Jaimovich and Rebelo (2009) emphasize the role of short-run inferiority of leisure in generating comovement. In their preferred preference specification the short-run is 37 years.
} 
and Preston (2009), an earlier version of this paper, shows that under certain conditions the model presented here induces co-movement in response to government spending and shocks to future technological opportunities.

A final implication of our model concerns the labor wedge — see Shimer (2009) for a review. Reflecting the improved empirical performance relative to standard real-business-cycle theory, the model's implied labor wedge accounts for limited variation in observed data at business cycle frequency. This contrasts with the findings of Chari, Kehoe, and McGrattan (2007) which argues that the labor wedge accounts for a substantial fraction of business cycles while investment shocks play an insignificant role in both the Great Depression and also postwar U.S. data. Our findings suggest that models of financial intermediation whose implications manifest themselves in the investment wedge, such as Bernanke, Gertler, and Gilchrist (1999), remain an important class of model to be developed. The source of different conclusions is our model is not nested in the class of models they consider. In fact, our

model implies a Frisch demand system that is consistent with various theories of unemployment, unlike standard real-business-cycle theory, allowing connections to be made to recent work by Hall (2009). Reinterpreting the model as a theory of unemployment, and using the unemployment rate as an observed series, gives similar estimation results on the role of investment shocks.

\section{The co-movement problem}

For a given level of TFP, real-business-cycle theory fails to produce co-movement between hours and consumption. Consider the following equilibrium labor market condition, derived under standard assumptions about preferences and technology,

$$
\left[\phi_{N}^{-1}+(1-\alpha) \alpha\right] \ln N_{t}=(1-\alpha) \ln T F P_{t}-\ln C_{t}+(1-\alpha) \alpha \ln K_{t},
$$

where $\phi_{N}>0$ is the Frisch elasticity of labor supply, $0<\alpha<1$ is the capital share in a Cobb-Douglas production function, and $N_{t}, C_{t}$ and $K_{t}$ are hours, consumption and capital. Capital is predetermined.

Without total factor productivity shocks, which shift the demand for labor, hours and consumption must be negatively correlated. On the one hand, any shock inducing strong substitution effects leads to a reduction in consumption and leisure to increase investment. 
On the other hand, any shock generating positive wealth effects increases consumption and leisure at the expense of investment. The real-business-cycle model predicts labor and consumption can move together, if, and only if, labor productivity co-moves more than proportionally to consumption. Joint expansion of total hours, consumption and investment requires a sufficiently strong increase in aggregate total factor productivity. As shown in Barro and King (1984) and Beaudry and Portier (2007a), this lack-of-comovement problem is fairly general in neoclassical models. It is robust to different forms of capital accumulation, including capacity utilization and investment-adjustment costs, and it holds in multi-sector models that are commonly used in macroeconomics. Moreover, the problem persists in medium-scale DSGE models which include various real and nominal rigidities and suboptimal monetary policy — see, for example, Justiniano, Primiceri, and Tambalotti (2011).

\section{The model}

We consider a single-good general equilibrium neoclassical stochastic growth model with the following features.

Households. Each household is composed of a continuum of members. There is perfect risk sharing within the household. The household decides whether a member will work (and how many hours to work) or not, and participating in the labor market entails a cost. The household also decides the consumption allocation of employed and non-employed members. The maximization problem for the household is

$$
E_{t} \sum_{T=t}^{\infty} \beta^{T-t}\left[e_{T} \cdot u\left(C_{H, T}^{e}, n_{T}\right)+\left(1-e_{T}\right) \cdot u\left(C_{H, T}^{n e}, 0\right)-\Phi_{X, T}\left(e_{T}\right)\right]
$$

where

$$
\begin{aligned}
u\left(C_{H}, n\right) & =\frac{C_{H}^{1-\sigma} \nu(n)-1}{1-\sigma} ; \nu(n)=\left(1+(\sigma-1) \kappa n^{1+\phi_{n}^{-1}}\right)^{\sigma} \\
C_{H, t}^{i} & =C_{t}^{i}-b C_{t-1} \text { for } i=e, n e
\end{aligned}
$$

with parametric assumptions $\sigma>1, \kappa>0, \phi_{n}^{-1}>0$ and $b>0 . n \in[0,1]$ is the number of hours worked. The variable $e_{t}$ denotes the fraction of household members that are working and household consumption is defined as

$$
C_{t}=e_{t} C_{t}^{e}+\left(1-e_{t}\right) C_{t}^{n e}
$$


where $C_{t}^{e}$ denotes consumption of employed members and $C_{t}^{n e}$ is consumption of the nonemployed. Following Abel (1990), household utility depends on lagged aggregate consumption, as in the "catching up with the Jonses" version of habit formation, giving habitadjusted consumption $C_{H, t}^{i}$. The function $\Phi_{X, t}\left(e_{t}\right)$ denotes a time-invariant cost of participation, which we keep distinct from the disutility incurred from hours worked — see, for example, Cho and Cooley (1994). It has the properties

$$
\Phi_{X, t}\left(e_{t}\right)=X_{t}^{1-\sigma} \Phi\left(e_{t}\right) \text {, where } \Phi^{\prime}\left(e_{t}\right), \Phi^{\prime \prime}\left(e_{t}\right)>0 \text {. }
$$

For a balanced-growth path to exist, the cost function is discounted by the level of labor augmenting technical progress $X_{t}$, where $\ln \left(X_{t}\right)-\ln \left(X_{t-1}\right)=\gamma_{t}$, with steady state $\bar{\gamma}>1$, and statistical properties to be described.

Each household is subject to the budget constraint

$$
C_{t}+I_{t}=R_{t}^{K} U_{t} K_{t}+\left(1-\tau_{w, t}\right) W_{t} N_{t}-T_{t}
$$

where $W_{t}$ denotes the real wage, $\tau_{w, t}$ denotes exogenous labor income taxes and $T_{t}$ is lump sum taxes which finance exogenous government spending $G_{t}$. There is no public debt. The total number of hours worked is $N_{t}=e_{t} n_{t}$. The household supplies capital services to firms at the competitive rental rate $R_{t}^{K}$. Capital services depend on the available stock of capital $K_{t}$, current investment $I_{t}$, and on the degree of utilization $U_{t}$. The law of capital accumulation is

$$
K_{t+1}=\mu_{t} I_{t}\left[1-\phi\left(\frac{I_{t}}{I_{t-1}}\right)\right]+\left[1-\delta\left(U_{t}\right)\right] K_{t}
$$

where $\mu_{t}$ is an investment wedge affecting the marginal efficiency of investment. Investmentadjustment costs in (3) depend on the function $\phi(\cdot)$ which satisfies

$$
\phi(1)=\phi^{\prime}(1)=0 \text { and } \phi^{\prime \prime}(1) \geq 0
$$

Finally, capital depreciation depends on the degree of capacity utilization according to the function

$$
\delta(\bar{U})=\delta, \delta^{\prime}(\bar{U})>0 \text { and } \delta^{\prime \prime}(\bar{U})>0
$$

Risk sharing. The necessary conditions for optimality are detailed in the appendix. We here discuss two important assumptions and their implications for optimal consumption allocations. The remaining properties of optimal household decisions are introduced later in 
the text as required. The first-order conditions with respect to consumption of the employed and non-employed imply the risk-sharing condition

$$
\frac{C_{t}^{e}-b C_{t-1}}{C_{t}^{n e}-b C_{t-1}}=1+(\sigma-1) \kappa n_{t}^{1+\phi_{n}^{-1}}
$$

so that employed members enjoy more consumption in compensation for the disutility of work effort. This compensation depends on the degree of nonseparability between consumption and leisure, which in turn varies with the curvature parameters $\sigma$ and $\phi_{n}$.

Nonseparability and perfect insurance. The utility function (1) is a reduced-form model of home production which assumes complementarity between consumption expenditures and hours worked. It is a standard utility function of the form suggested by King, Plosser, and Rebelo (1988) and recently adopted in Shimer (2009) and Trabandt and Uhlig (2009). In particular: (i) it is consistent with long-run growth; (ii) it features a constant Frisch elasticity of labor supply and a constant intertemporal elasticity of substitution of consumption (net of habit); and iii) it has a flexible enough functional form to calibrate the degree of consumption-hours complementarity consistently with microeconomic evidence a key difference from preference structures of the kind proposed by Greenwood, Hercowitz, and Huffman (1988).

In this model the joint behavior of consumption expenditures and labor supply are implicitly driven by substitution between market-produced and home-produced goods. This assumption is motivated by recent research suggesting that: i) households substitute between market and non-market work over the business cycle; and ii) labor supply decisions drive work-related consumption expenditures, which are a significant component of non-durable expenditures. Using the American Time Use Survey, Aguiar, Hurst, and Karabarbounis (2011) show that in the past recession households reallocated a substantial fraction of market work to non-market activities, such as home production and maintenance, shopping time, care for other adults and child care. In particular, they suggest that the bulk of this reallocation was tied to changes in employment status. Aguiar and Hurst (2008) show that the hump-shaped profile of nondurable consumption expenditures over the life-cycle is almost entirely accounted for by a decline in work-related expenditures, which cover roughly $60 \%$ of nondurable consumption expenditures. These comprise clothing and transportation, which are inputs into market labor supply and food away from home, which is directly 
linked to home production activities. They provide evidence that the drop in work-related expenditures after middle age is almost entirely driven by labor supply decisions.

The assumption of perfect insurance greatly simplifies the analysis and gives emphasis to the observed relation between consumption and hours worked as coming from non-separable preferences and not incomplete financial markets. There is much evidence that temporary income shocks are well insured, while permanent shocks are only partially insured — see Attanasio and Davis (1996), Blundell, Pistaferri, and Preston (2008) and Heathcote, Storesletten, and Violante (2011). Two observations about this evidence are warranted, relating to the adoption of non-separable preferences. First, Aguiar and Hurst (2008) demonstrate that estimates of the importance of uninsured permanent shocks to income in explaining consumption dispersion over the life-cycle is inflated by failing to account for non-separabilities. Second, taking data from the Consumer Expenditure Survey, Heathcote, Storesletten, and Violante (2011) document a positive correlation between hours and consumption in the cross section of households, after controlling for income dispersion arising from partially insurable permanent income shocks. Non-separability can account for the positive correlation between hours worked and consumption. Regardless, we view perfect insurance as a tractable approximation to reality in the spirit of Hall (2009).

Firms. Output is produced by perfectly competitive firms with the Cobb-Douglas production function

$$
Y_{t}=\left(U_{t} K_{t}\right)^{\alpha}\left(X_{t} N_{t}\right)^{1-\alpha}
$$

where $X_{t}$ denotes labor-augmenting technical progress. Firm demand for labor and capital services are given by

$$
R_{t}^{K}=\alpha \frac{Y_{t}}{U_{t} K_{t}}
$$

and

$$
W_{t}=(1-\alpha) \frac{Y_{t}}{N_{t}}
$$

This completes the description of the model.

\section{Investment Shocks and the Business Cycle}

The economy evolves in response to fluctuations in four exogenous processes: technology $\gamma_{t}$; labor income taxes $\tau_{w, t}$; government purchases $G_{t}$; and disturbances to investment $\mu_{t}$. 
Primary focus is on the investment disturbances, $\mu_{t}$, which are identified as innovations to the marginal efficiency of investment — details are described in section 7.1. This emphasis is motivated primarily by Gilchrist, Ortiz, and Zakrajsek (2009) and Gilchrist and Zakrajšek (2012) which show that movements in credit spreads and, in particular, excess bond premia, have statistically and economically significant implications for economic activity in the U.S.. ${ }^{8}$ Increases in excess bond premia lead to a significant decline in consumption, investment and output. Moreover, orthogonalized shocks to the excess bond premium can explain a nontrivial part of business fluctuations. Fisher (2006) also provides evidence that investment shocks, measured from the relative price of investment data in Cummins and Violante (2002), are an important determinant of business fluctuations.

As in Chari, Kehoe, and McGrattan (2007), Christiano and Davis (2006) and Justiniano, Primiceri, and Tambalotti (2011) we interpret these shocks as measuring fluctuations in the equilibrium supply of credit affecting the creation of productive capital. Movements in the marginal efficiency of investment have similar implications for consumption, output, investment and hours as a shock to the efficiency of the financial intermediation process in Bernanke, Gertler, and Gilchrist (1999)-type models where financial frictions are explicitly modelled. Both models suffer from the co-movement problem described above. As documented in Christiano, Motto, and Rostagno (2013) and Gilchrist and Zakrajsek (forthcoming), shocks to the efficiency of financial intermediation are better candidates to explain business cycles because, in contrast with shocks to the marginal efficiency of investment, they have implications for asset prices that are consistent with the data. The focus on marginal efficiency of investment shocks in this paper reflects the aim to keep the model as simple as possible; the results discussed below also apply to a model where financial frictions are more fully developed.

\section{Non-separability, employment and co-movement}

This section outlines the basic mechanism generating co-movement. Using a special case of the model, analytic results on the conditions for co-movement are presented. Various extensions are then discussed.

\footnotetext{
${ }^{8}$ Looking at financial variables during the 2007-09 crises, movements of these spreads are shown to be connected to changes in the supply of credit.
} 


\subsection{Simple example}

To provide intuition for the co-movement result, consider a special case of the model with no investment-adjustment costs, no habit formation, no capacity utilization and no intensive margin of labor supply. Assume for simplicity of exposition that there is a fixed cost of participating so that $\Phi_{e}(\bar{e}) \rightarrow 0$. Lastly, assume that $X_{t}=1$ and $\tau_{w, t}=G_{t}=0$. Details of the log-linearized model are described in the appendix.

Following Beaudry and Portier (2007b), exploit the model's intratemporal conditions to derive parametric restrictions required for co-movement between consumption, hours and investment. When employed members of the household work a fixed number of hours $\bar{n}$, the first-order condition for employment requires

$$
C_{t}^{e}-C_{t}^{u}=\frac{(\sigma-1)}{\sigma} W_{t} \bar{n} .
$$

The first-order conditions for consumption allocation imply

$$
\frac{C_{t}^{e}}{C_{t}^{u}}=1+(\sigma-1) \kappa \bar{n}^{1+\phi_{n}^{-1}}
$$

which states consumption of the employed and non-employed move proportionally. Aggregate consumption and the real wage are defined as in (2) and (7), while the aggregate resource constraint is

$$
C_{t}+I_{t}=Y_{t}
$$

Log-linearizing these intratemporal conditions and rearranging using steady-state restrictions yields the constant-consumption aggregate labor supply condition

$$
\hat{C}_{t}=\hat{W}_{t}+\frac{(1-\omega)}{1+\left(\bar{e}^{-1}-1\right) \omega} \hat{N}_{t}
$$

where $N_{t}=\bar{n} e_{t}$ and $\omega=\bar{C}^{n e} / \bar{C}^{e}$ is the steady-state ratio of non-employed-to-employed consumption and for any variable $x_{t}, \hat{x}_{t} \equiv \ln \left(x_{t} / \bar{x}\right)$ the log-deviation from steady state. When $\omega=1$, equivalently $\sigma=1$, preferences are separable in consumption and leisure. ${ }^{9}$ The consumption of employed and non-employed are then equal and the model implies a perfectly elastic labor supply, as in Hansen (1985) and Rogerson (1988). With $0<\omega<1$, employed members of the household consume more than the non-employed. This induces a positive

\footnotetext{
${ }^{9}$ The relationaship between $\sigma$ and $\omega$ is shown formally in the appendix.
} 
relationship between aggregate consumption and total hours supplied to the market, for a given real wage. Recall real-business-cycle theory implies a negative correlation. It is this distinction, now analyzed in detail, that permits co-movement for non-TFP disturbances.

Since capital is predetermined in the current period, (7) implies a negative relation between the real wage and the number of hours worked. In log-linear terms, and ignoring terms in the capital stock,

$$
\hat{W}_{t}=-\alpha \hat{N}_{t}
$$

Substituting this expression into (10) yields the relation

$$
\hat{C}_{t}=m_{\omega} \hat{N}_{t}
$$

between total hours and aggregate consumption, where

$$
m_{\omega}=\frac{(1-\omega)}{1+\left(\bar{e}^{-1}-1\right) \omega}-\alpha
$$

The constant $m_{\omega}$ comprises two terms. The first is positive, indicating that an increase in hours worked increases aggregate consumption because the fraction of employed rises, and the employed consume more in equilibrium. This is a composition effect arising from consumption heterogeneity to which discussion will return. The second term is negative, reflecting that decreasing returns to the labor input imply increases in hours decrease the real wage, with concomitant declines in aggregate consumption. Sufficiently low values of $\omega$ guarantee positive co-movement between consumption and total hours worked.

Combining the resource constraint, the production function and (11) yields the relation between investment and hours worked

$$
\frac{\bar{I}}{\bar{Y}} \hat{I}_{t}=\left(1-\alpha-\frac{\bar{C}}{\bar{Y}} m_{\omega}\right) \hat{N}_{t}
$$

where $\bar{I}, \bar{C}$ and $\bar{Y}$ are the steady-state values of investment, consumption and output. The coefficient on employment is positive and increasing in $\omega .{ }^{10}$ The joint dynamics of investment and hours place no additional requirements for co-movement. The following proposition summarizes the result.

\footnotetext{
${ }^{10}$ Note that for $\omega \rightarrow 0$$$
\frac{C}{Y}\left(\frac{1-\omega}{1+\left(\bar{e}^{-1}-1\right) \omega}-\alpha\right) \rightarrow \frac{C}{Y}(1-\alpha)<(1-\alpha) .
$$ 
Proposition 1 For a given $\bar{e} \in(0,1)$ and $\alpha \in(0,1)$, there exists an $\omega^{*}$ such that for $0<$ $\omega<\omega^{*}$ the economy displays positive co-movement between aggregate hours, consumption and investment.

It is worth pointing out that perfectly elastic labor supply does not imply co-movement. Consumption heterogeneity from the non-separability of leisure and consumption is central to the result.

\subsection{Some Generalizations}

Two extensions permit analytical results: the inclusion of capacity utilization and habit formation. Both enhance co-movement. Neither generates co-movement if $\omega=1$, that is if $\bar{C}^{n e}=\bar{C}^{e}$.

Capacity utilization. Capacity utilization increases the ability of the model to generate co-movement by mitigating the effects of diminishing returns to labor input. Combining log-linear approximations to the first-order condition for capital utilization in the household problem

$$
\mu_{t} R_{t}^{K}=\delta^{\prime}\left(U_{t}\right)
$$

and (26) gives

$$
\hat{U}_{t}=\frac{(1-\alpha) \hat{N}_{t}+\hat{\mu}_{t}}{\epsilon_{\delta}+1-\alpha}
$$

where $\epsilon_{\delta} \equiv \delta^{\prime \prime}(\bar{U}) \bar{U} / \delta^{\prime}(\bar{U})>0$. The wage then can be expressed as

$$
\hat{W}_{t}=\left(\frac{1-\alpha}{\epsilon_{\delta}+1-\alpha}-1\right) \alpha \hat{N}_{t}+\frac{\alpha}{\epsilon_{\delta}+1-\alpha} \hat{\mu}_{t}
$$

which, substituted into (10), yields

$$
\hat{C}_{t}=\bar{m}_{\omega} \hat{N}_{t}+\frac{\alpha}{\epsilon_{\delta}+1-\alpha} \hat{\mu}_{t}
$$

where

$$
\bar{m}_{\omega}=\frac{(1-\omega)}{1+\left(\bar{e}^{-1}-1\right) \omega}-\left(1-\frac{1-\alpha}{\epsilon_{\delta}+1-\alpha}\right) \alpha .
$$

It is evident that $\bar{m}_{\omega}>m_{\omega}$ so that co-movement can be obtained for higher values of $\omega$. These expressions nest the results for the model without variable capacity utilization. Specifically, when $\epsilon_{\delta} \rightarrow \infty$, so that depreciation costs become infinitely elastic with respect to utilization rates, the relation between aggregate consumption and hours is the same 
as above, that is: $\bar{m}_{\omega}=m_{\omega}$. Conversely, as $\epsilon_{\delta} \rightarrow 0$, depreciation costs become completely inelastic and co-movement is guaranteed for every $\omega<1$. Furthermore, co-movement obtains because $\partial \hat{N}_{t} / \partial \hat{\mu}_{t}$ is positive in equilibrium, as households intertemporally substitute labor to take advantage of higher marginal efficiency of investment. The relation between investment and hours becomes

$$
\frac{\bar{I}}{\bar{Y}} \hat{I}_{t}=\left[(1-\alpha)\left(1+\frac{\alpha}{\epsilon_{\delta}+1-\alpha}\right)-\frac{\bar{C}}{\bar{Y}} \bar{m}_{\omega}\right] \hat{N}_{t}+\left(1-\frac{\bar{C}}{\bar{Y}}\right) \frac{\alpha}{\epsilon_{\delta}+1-\alpha} \hat{\mu}_{t} .
$$

In this case, it is straightforward to show that, for a given $\hat{\mu}_{t}$, co-movement between total hours and investment is guaranteed for every value of $\epsilon_{\delta}$.

Habit formation. Consider now the simple model where only habit formation is added. Using the first-order condition for employment, individual consumption of employed and non-employed, and the definition of aggregate consumption, provides

$$
\hat{C}_{t}=\tilde{m}_{\omega} \hat{N}_{t}
$$

where

$$
\tilde{m}_{\omega}=\frac{(1-\omega)}{1+\left(\bar{e}^{-1}-1\right) \omega}-(1-b) \alpha .
$$

As in the case of capacity utilization, habit formation per se does not generate positive co-movement. Coupled with non-separable preferences and the extensive margin it facilitates co-movement by making some part of current consumption predetermined. This weakens the effect of variations in the real wage on aggregate consumption. Similarly, the relation between investment and hours becomes ${ }^{11}$

$$
\frac{I}{Y} \hat{I}_{t}=\left(1-\alpha-\frac{C}{Y} \tilde{m}_{\omega}\right) \hat{N}_{t}
$$

The discussion above can be summarized by the following proposition.

Proposition 2 Consider the model with habit formation and capacity utilization:

1) for $\omega=1, m_{\omega} \leq 0$ independently of $\epsilon_{\delta}$ and $b$;

2) for $\omega<1, \frac{\partial \omega^{*}}{\partial \epsilon_{\delta}}<0$ and $\frac{\partial \omega^{*}}{\partial b}>0$, where $\omega^{*}$ is such that for $0<\omega<\omega^{*}$ the economy displays positive co-movement between aggregate hours, consumption and investment.

\footnotetext{
${ }^{11}$ Again, a sufficient restriction for positive comovement between hours and investment is $\frac{\bar{C}}{\bar{Y}}<1-\alpha$. In a plausible calibration values of $\omega>0.5$ imply positive comovement even if $\frac{\bar{C}}{Y}>1-\alpha$.
} 
To give an idea of the role of $\omega$ in a model with both capacity utilization and habit formation, suppose $\alpha=0.32, \bar{e}=0.78, \epsilon_{\delta}=0.404$ and $b=0.35$. Then positive co-movement obtains for values of $\omega$ as high as 0.9. This suggests that co-movement can be obtained for reasonable values of $\omega$. This is discussed further in the calibration section.

Intensive margin. Thus far it has been assumed that variations in total hours are driven only by changes in employment. However, in U.S. data, the intensive margin plays a non-negligible role in explaining movement in hours worked. It is therefore important to include this margin to evaluate properly the strength of the proposed mechanism.

We restrict preferences to be consistent with both concavity and normality of consumption and leisure. The necessary restriction on preferences are described by the following proposition, employing the definitions, $s_{e} \equiv \bar{C}^{e} \bar{e} / \bar{C}$, the share of employed consumption in aggregate consumption, and $\psi=\bar{W} \bar{N} / \bar{C}$, the steady-state labor income flow over aggregate consumption. ${ }^{12}$

Proposition 3 Let $\phi_{n}$ be the Frisch elasticity of the supply of hours worked. Assume $\omega s_{e}-$ $b \bar{\gamma}^{-1} \bar{e}>0$ and let $\bar{\phi}_{n}=\frac{s_{e}-\bar{e} b \bar{\gamma}^{-1}}{\left(1-\sigma^{-1}\right) \psi}$. For $0<\phi_{n}<\bar{\phi}_{n}$

1) the utility function is concave;

2) consumption and leisure are normal goods.

Because of the restrictions imposed by concavity and normality, the intensive margin has important implications for co-movement. Log-linearizing the first-order condition for individual hours

$$
\frac{C_{t}^{e}-b C_{t-1}}{\sigma-1} \cdot \frac{\nu^{\prime}\left(n_{t}\right)}{\nu\left(n_{t}\right)}=W_{t}
$$

gives the constant-consumption labor supply equation

$$
\left(\phi_{n}^{-1}-\bar{\phi}_{n}^{-1}\right) \hat{n}_{t}=\hat{W}_{t}-s_{e}\left(s_{e}-\bar{e} b \bar{\gamma}^{-1}\right)^{-1} \hat{C}_{t}^{e}
$$

where lagged aggregate consumption is predetermined and therefore ignored. Given the restrictions on preferences from proposition 3, (13) shows that normality of preferences implies a negative relation between individual hours and individual consumption absent technology shocks — see Bilbiie (2009). ${ }^{13}$ Introducing the intensive margin necessarily

\footnotetext{
${ }^{12}$ The restrictions are derived by studying the curvature of the utlity function at the steady-state. They have therefore only local validity. See the appendix for details.

${ }^{13}$ The final two terms in brackets are irrelevant to comovement because one is predetermined and the other exogenous. Also note that the term $s_{e}-\bar{e} b \bar{\gamma}^{-1}$ is assumed to be positive to ensure marginal utility of consumption is positive in steady state.
} 
weakens co-movement. However, the non-separability of preferences implies a smaller effect on consumption from a change in hours worked than in the standard case of separable preferences where $\bar{\phi}_{n}^{-1}=0$. This property of non-separable preferences reveals the extensive margin as crucial in obtaining co-movement.

Aggregate consumption satisfies the log-linear approximation

$$
\hat{C}_{t}=s_{e} \hat{C}_{t}^{e}+\left(1-s_{e}\right) \hat{C}_{t}^{u}+(1-\omega) s_{e} \hat{e}_{t} .
$$

It depends on the weighted sum of the individual consumption of the employed and nonemployed, and also the employment rate. Changes in participation generate a composition effect on aggregate consumption. The magnitude of this effect depends on $\omega$, the consumption share of the non-employed. In the case of equal consumption of employed and nonemployed, $\omega=1$, there is no employment effect on aggregate consumption. In the case where most fluctuations in total hours are determined by the intensive margin, $\hat{e}_{t} \approx 0$, there is similarly no composition effect, and aggregate consumption would mimic individual consumption, as in standard real-business-cycle theory. In this case the assumed normality of preferences would induce negative co-movement between consumption and hours.

\section{Calibration of the Benchmark Model}

The model is calibrated to U.S. data. The time period is a quarter. We set the discount factor $\beta=0.99$, the capital share $\alpha=0.32$ and the depreciation rate of capital to $\delta=0.025$. These parameter values are common in the real-business-cycle literature. The steady-state ratio of government spending to output is $\bar{g} / \bar{y}=0.2$, roughly consistent with the nondurable consumption- and investment-to-GDP ratios in our sample. Concerning the elasticity of capacity utilization, we follow Greenwood, Hercowitz, and Huffman (1988) and set $\epsilon_{\delta}=$ $\delta^{\prime \prime}(\bar{U}) \bar{U} / \delta^{\prime}(\bar{U})=\theta-1=0.404$ as implied by the model's steady state.

Labor supply. The steady-state fraction of household members that participate in the labor market is $\bar{e}=0.78$, in line with the prime-age (between 25 and 55 years old) employment-to-population ratio since the 1980s. The Frisch elasticity of hours is $\phi_{n}=1$ and the Frisch elasticity of employment is given by $\phi_{n} / \phi_{e}=0.3$. The elasticity of labor supply on the intensive margin is consistent with a large range of evidence - see Hall (2009) for a 
review. Together with the extensive margin it implies an aggregate labor supply elasticity of 4.33, roughly twice as large as the standard real-business-cycle calibration with only an intensive margin. The choice of the elasticity of labor supply at the extensive margin approximates the observed relative volatility of employment to total hours in the data. ${ }^{14}$

Consumption of employed and non-employed. The baseline specification assumes $\omega=0.77$, implying that non-employed members of the household consume $23 \%$ less than employed members. The number is motivated by the following exercise. We use CEX data on U.S. household expenditures for $1980-2007 .{ }^{15}$ The data set includes a representative sample of household expenditures, wages and hours worked. Restricting attention to households where the head is prime age, the sample is divided into two groups: households that work less than 2040 hours in a year (which corresponds to the $25^{\text {th }}$ percentile) and the rest. This threshold approximates the labor supply of one member of the household's full-time equivalent attachment to the labor market. Because the wage is included in the estimation, the number of hours worked in each household is restricted to be positive. The inclusion of wages helps control for differences in permanent income. Different measures of nondurable consumption are then regressed on a dummy variable, defined by the number of hours worked, and several control variables. The dummy measures by what percentage consumption is higher for the group that works more than 2040 hours per year. The control variables include, age, education, race, region, number of household members, wages and years.

Table 1 shows the estimates and associated 95\% confidence intervals. Four regressions are reported. The first row gives estimates of the coefficient on the dummy variable for two different samples. Using non-durable expenditures identifies a 25 percent difference in consumption expenditures between employed and non-employed households. The final column gives the associated confidence interval. When the sample is restricted to those households supplying at least 260 hours worked a year, the estimate is 23 percent. The bottom rows give results for a broader measure of expenditures which include an estimate of the service flow from vehicle and housing purchases. Similar results obtain. Evident in these results is the strong correlation in the cross-section between hours worked and

\footnotetext{
${ }^{14}$ Similar calibration is used in Dotsey and King (2006). See also Table 5 below.

${ }^{15}$ We thank Gianluca Violante for suggesting and providing the data. The data used here are from Heathcote, Perri, and Violante (2010). A detailed description of the dataset can be found in that paper.
} 
consumption expenditures at the level of the household.

Table 1. Consumption and hours worked in CEX data

\begin{tabular}{lcc}
\hline \hline & $\begin{array}{c}\text { Coefficient on } \\
\text { Dummy }\end{array}$ & $95 \%$ C.I \\
\cline { 2 - 3 } Nondurable expenditures* & & \\
Full Sample & $25 \%$ & $24 \%, 27 \%$ \\
Hours Restricted & $23 \%$ & $22 \%, 25 \%$ \\
Nondurable expenditures ${ }^{* *}$ & & \\
Full Sample & $30 \%$ & $29 \%, 31 \%$ \\
$\quad$ Hours Restricted & $27 \%$ & $26 \%, 29 \%$ \\
\hline \hline
\end{tabular}

Note: * denotes nondurable expenditures only. ${ }^{* *}$ denote nondurable expenditures with estimate of the service flow from vehicles and housing.

How do we interpret the results? There is a discrepancy between model-based and data-based concepts of consumption. Our model is not a theory of within household behavior, and, moreover, the data do not allow us to measure the consumption of individual members of the household. What we measure is the ratio of total consumption of households working less than 2040 hours to the total consumption of households working more than 2040 hours. That is

$$
C^{\text {ratio }}=\frac{C_{H \leq 2040}}{C_{H>2040}}=\frac{C_{H \leq 2040}^{1}+C_{H \leq 2040}^{2}}{C_{H>2040}^{1}+C_{H>2040}^{2}}
$$

with obvious notation, and where the second equality makes clear the dependency of total household consumption on individual consumption. From this household-level quantity, defined by the first equality, we wish to infer an individual-level quantity - the consumption differential between employed and non-employed individuals — implicit in the second equality. In conducting this inference two points warrant note. First, the number of hours worked when computing this ratio is not necessarily zero as assumed in the model for the non-employed. This tends to understate the decline in consumption when transitioning from employment to non-employment. Second, the ratio depends on the allocation of consumption within the household. For example, suppose that the denominator in the right 
most expression in (14) describes the consumption of two working members of the household, while the numerator describes one member working full time and one not working or working less hours. If each household member has the same amount of consumption then

$$
C^{\text {ratio }}=\frac{C^{n e}}{C^{e}}
$$

where a household with only one member employed consumes less. If instead household members have different consumption levels related to the hours each works then

$$
C^{\text {ratio }}=\frac{C^{n e}+C^{e}}{2 C^{e}}=\frac{1+C^{n e} / C^{e}}{2},
$$

which implies an even lower $C^{n e} / C^{e}$. The baseline calibration takes a cautious approach, assuming perfect insurance within the household and setting the ratio between employed and non-employed consumption to be equal to $0.77 \%$ - the smallest consumption differential implied by the estimates in Table 1. Finally, our finding are roughly consistent with Aguiar and Hurst (2008), documenting in the CEX that nondurable consumption expenditures peak in middle age and are $25 \%$ higher than at 65 ; this drop in expenditures is shown to be closely linked to labor supply choices after middle age, and in particular retirement.

Preferences. Using the steady-state restrictions of the model, the first-order condition with respect to employment yields

$$
\frac{\sigma}{\sigma-1}(1-\omega) s_{e}=\psi-\frac{\bar{\lambda}^{-1} \Phi_{e}(\bar{e}) \bar{e}}{\bar{c}}
$$

where the marginal disutility of working can be expressed as a fraction $\zeta$ of after-tax wage earnings

$$
\bar{\lambda}^{-1} \frac{\Phi_{e}(\bar{e}) \bar{e}}{\bar{c}}=\frac{\zeta\left(1-\bar{\tau}_{w}\right) \bar{w} \bar{N}}{\bar{c}}=\zeta \psi
$$

The parameter $\psi$, denoting total wage compensation (after taxes) as a fraction of total consumption, is set equal to 0.85 , roughly in line with the share of wages over nondurable consumption in the U.S.. In steady state, it implies a labor-tax wedge of $\bar{\tau}_{w}=0.3$. In addition, steady state implies the restriction $1-\zeta=1 /\left(1+\phi_{n}^{-1}\right)$, which defines the value of not working as a fraction of the flow value of employment (net earnings). ${ }^{16}$ For example,

\footnotetext{
${ }^{16}$ This can be seen by inspecting the steady-state employment first-order condition:
}

$$
\left[u\left(\bar{c}^{n e}, 0\right)-u\left(\bar{c}^{e}, \bar{n}\right)\right] \bar{\lambda}^{-1}+\bar{c}^{e}-\bar{c}^{u}=\left(1-\bar{\tau}_{w}\right) \bar{w} \bar{n}(1-\zeta) .
$$


a value of $\zeta$ closer to zero would correspond to the calibration of Hagedorn and Manovskii (2008). Our calibration of $\phi_{n}=1$ yields $\zeta=0.5$, which is close to the values used in Hall (2005) and Shimer (2005).

For a given value of $\omega$, the parameter $\sigma$ is obtained by the steady-state relationship

$$
\sigma^{-1}=1-\frac{(1-\omega) \psi^{-1} s_{e}}{1-\zeta}
$$

which gives $\sigma=1.8$. This parameter implies a positive Frisch cross-elasticity of consumption with respect to the real wage, which is equal to

$$
\phi_{n}\left(1-\sigma^{-1}\right) \frac{\psi}{s_{e}}=0.46
$$

consistent with values used by Hall (2009) and Trabandt and Uhlig (2012). This crosselasticity depends both on $\sigma$ and the Frisch elasticity of labor supply.

For the external habit parameter we assume $b=0.35$, consistent with the empirical evidence in Ravina (2011). The implied intertemporal elasticity of substitution for consumption is

$$
I E S^{e}=\sigma^{-1}\left(1-\bar{e} \bar{\gamma}^{-1} b s_{e}^{-1}\right)=0.37
$$

for the employed agents and

$$
I E S^{n e}=\sigma^{-1}\left(\omega-\bar{e} \bar{\gamma}^{-1} b s_{e}^{-1}\right)=0.32
$$

for the non-employed. To put this in perspective, the IES of a representative agent with separable preferences, but with a higher habit parameter (i.e. $b=0.7$ as usually estimated in DSGE models) is lower than 0.3. Finally, we set a low level of investment adjustment costs, with $\phi^{\prime \prime}=0.2$, delivering a gradual and hump-shaped response of investment and hours investment shocks. This is consistent with empirical evidence from structural VARs in Fisher (2006) and Gilchrist and Zakrajšek (2012). The benchmark calibration is summarized in Table 2.

Table 2: Benchmark Calibration.

\begin{tabular}{lllllllllllll}
\hline \hline$\omega$ & $\beta$ & $\phi_{n}$ & $\zeta$ & $\phi_{n} / \phi_{e}$ & $\epsilon_{\delta}$ & $\phi^{\prime \prime}(1)$ & $\bar{e}$ & $b$ & $\alpha$ & $\delta$ & $\bar{\gamma}$ & $\sigma$ \\
\hline 0.77 & 0.99 & 1 & 0.5 & 0.3 & 0.404 & 0.2 & 0.78 & 0.35 & 0.32 & 0.025 & 1.0041 & 1.8 \\
\hline
\end{tabular}




\section{Macroeconomic Co-movement}

This section provides a quantitative evaluation of the model. The estimated model establishes that innovations to the marginal efficiency of investment are an important driver of business cycles, accounting for a substantial fraction of observed variation in consumption, hours and investment. Conditional on such disturbances the model exhibits positive co-movement which is the source of empirical success. Reflecting this success, the model implies a smaller labor wedge at business-cycle frequency than real-business-cycle theory.

\subsection{Estimation and model evaluation}

This section evaluates whether shocks to the marginal efficiency of investment can generate business fluctuations observed in the U.S. post-war period. The model's four disturbances

$Z_{t}=\left(\hat{\gamma}_{t}, \hat{\tau}_{t}^{w}, \hat{G}_{t}, \hat{\mu}_{t}\right)^{\prime}$ are estimated using quarterly data on real GDP, consumption, investment growth, and total hours worked over the sample 1955Q1-2010Q3. The variables are constructed as follows with Haver Analytics codes in parenthesis. Output is real gross domestic product (GDPH); nominal consumption is computed as the sum of nondurable goods (CN) and services (CS); nominal investment is the sum of private nonresidential investment structures (FNS), equipment and software (FNE), private residential investment (FR) and consumption durable goods (CD). Consumption and investment are converted to real terms using the GDP deflator (GDP/GDPH). Total hours corresponds to the Francis and Ramey (2009) measure: it displays smaller low-frequency movements compared to nonfarm business total hours from the establishment survey because it accounts better for sectoral shifts in hours and changing age composition in the working-age population. All variables are divided by the civilian non-institutional population (age 16 and older).

The benchmark model assumes the disturbances evolve according to the data-generating process

$$
Z_{t}=P Z_{t-1}+V \eta_{t}, \quad \eta_{t} \sim N(0, I)
$$

where the following assumptions are made: i) the matrix $P$ has three restrictions: $P(1,4)=$ $P(2,4)=P(3,4)=0$; and ii) the matrix $V$ is lower triangular. The first assumption guarantees that the lagged investment wedge does not affect any of the other wedges. Given the order of the variables, the second assumption insures that innovations to the investment 
wedge have no contemporaneous effect on the other wedges. This specific identification measures investment shocks which are orthogonal to movement in the other wedges. This makes it possible to evaluate the role of investment shocks in explaining the U.S. business cycle, holding other wedges constant.

Similar in spirit to Chari, Kehoe, and McGrattan (2007), two other identification strategies are considered. One leaves $P$ unrestricted. The other assumes $P$ and $V$ are diagonal matrices giving independent wedges, which serves to identify all shocks. The model is estimated using maximum likelihood. The point estimates of $P$ and $V$ together with the $5^{\text {th }}$ and $95^{t h}$ percentiles of 500 bootstrapped replications can be found in the appendix.

Discussion. It is useful to compare the approach of this paper to Chari, Kehoe, and McGrattan (2007) and Christiano and Davis (2006). Chari, Kehoe, and McGrattan (2007) do not identify shocks but focus on wedges - which in principle are linear combinations of the fundamental innovations. Consistently, their paper focuses on the unrestricted version of (15) and evaluates the evolution of each wedge over the business cycle, holding other wedges constant, finding a prominent role for the labor wedge. Our model's implications for the labor wedge are discussed below. Christiano and Davis (2006) explicitly identify an investment shock from an unrestricted version of (15) but follow an alternative identification strategy. Instead of identifying orthogonal movements in the investment shock relative to other wedges, the approach adopted in this paper, they allow shocks to the investment wedge to have spillover effects onto the other wedges. They identify the effects of the investment shocks by locating the rotation matrix from wedges to innovations that maximizes the role of innovations to the investment-specific technology shock. They find that investment shocks have an important role in business-cycle fluctuations; however, the spillovers from investment shocks to other wedges are important to their result.

Model fit. To evaluate model fit, Table 3 compares the likelihood from the baseline model with several alternatives. 
Table 3: Model Evaluation

\begin{tabular}{|c|c|c|c|}
\hline \multirow{3}{*}{$\begin{array}{l}\text { Identification: } \\
\ln -L\end{array}$} & \multicolumn{3}{|c|}{ Baseline model } \\
\hline & Restr. VAR & Unrestr. VAR & Indep. wedges \\
\hline & -146.37 & -142.76 & -262.36 \\
\hline & \multicolumn{3}{|c|}{ Restricted VAR } \\
\hline Model: & Baseline & Separable & $\mathrm{RBC}$ \\
\hline $\ln -L$ & -146.37 & -166.85 & -183.01 \\
\hline
\end{tabular}

The top row compares the baseline model with alternative assumptions about the datagenerating process for the wedges in (15). The unrestricted model performs slightly better: a likelihood ratio test on the three restrictions yields a $\mathrm{P}$-value of 0.065 , indicating that the restrictions are not rejected by the data at conventional confidence levels. To put this in perspective, a model with fully independent wedges is strongly rejected by the data. A likelihood ratio test of the fifteen restrictions results in a $\mathrm{P}$-value of zero. The difference in fit is also apparent by direct inspection of the log-likelihoods.

The bottom row compares our baseline models with two alternatives. The first model shares the same baseline specification but for the assumption of separable preferences (which implies $\sigma=\omega=1$ ). The second model is the standard real-business-cycle model with separable preferences, no capacity utilization, habit formation or investment-adjustment costs, and an aggregate elasticity of labor supply of 2. As formal statistical tests are not possible across these models, comparing the likelihoods of the model strongly suggests that the baseline specification provides a better fit to the data.

Business cycle moments. Table 4 compares model-generated business cycle moments with the U.S. sample, with $5^{\text {th }}$ and $95^{\text {th }}$ percentiles of 500 bootstrapped replications in parenthesis. The statistics are obtained by detrending both model-generated and sample variables using the HP-filter. 
Table 4: Moments

\begin{tabular}{|c|c|c|c|c|c|}
\hline & Data & Baseline & & Data & Baseline \\
\hline $100 \cdot \sigma_{Y}$ & 1.63 & $\begin{array}{c}1.77 \\
(1.57,1.98)\end{array}$ & $\rho(I, Y)$ & 0.85 & $\begin{array}{c}0.94 \\
(0.93,0.96)\end{array}$ \\
\hline$\sigma_{C} / \sigma_{Y}$ & 0.53 & $\begin{array}{c}0.48 \\
(0.43,0.52)\end{array}$ & $\rho(N, Y)$ & 0.87 & $\begin{array}{c}0.88 \\
(0.84,0.91)\end{array}$ \\
\hline$\sigma_{I} / \sigma_{Y}$ & 3.82 & $\begin{array}{c}3.52 \\
(3.38,3.69)\end{array}$ & $\sigma_{e} / \sigma_{N}$ & 0.80 & $\begin{array}{c}0.77 \\
(0.75,0.80)\end{array}$ \\
\hline$\sigma_{N} / \sigma_{Y}$ & 0.95 & $\begin{array}{c}0.78 \\
(0.74,0.83)\end{array}$ & $\sigma_{n} / \sigma_{N}$ & 0.40 & $\begin{array}{c}0.25 \\
(0.24,0.27)\end{array}$ \\
\hline$\rho(C, Y)$ & 0.77 & $\begin{array}{c}0.73 \\
(0.65,0.81) \\
\end{array}$ & $\rho(e, n)$ & 0.47 & $\begin{array}{c}0.89 \\
(0.71,0.93) \\
\end{array}$ \\
\hline
\end{tabular}

The model produces familiar business-cycle statistics. Business-cycle moments for individual weekly hours and employment (as measured by the BLS establishment survey covering the non-farm private business sector) are included even though they are not used in estimation. The model provides a reasonable characterization of the data. However, the model predicts individual hours and employment to be highly correlated while, in the data, individual hours display roughly half of the correlation with employment. This explains a relative standard deviation between individual hours and employment of about 25\%, compared to $40 \%$ in the data. ${ }^{17}$

\subsection{Investment shocks and the business cycle}

As explained in the previous section, our identification of investment shocks permits evaluating their role in U.S. business cycles, holding other wedges constant. Table 5 shows what fraction of the variance of each model variable is explained by investment shocks. ${ }^{18}$ Numbers in parenthesis are $90 \%$ confidence intervals computed using bootstrapped estimates. ${ }^{19}$

\footnotetext{
${ }^{17}$ Permitting exogenous fluctuations in the marginal cost of participation would likely induce a negative correlation between individual hours and employment, reconciling the model with the data.

${ }^{18}$ The variance decomposition is calculated using 5000 replications of simulated time series with sample size corresponding to the data.

${ }^{19}$ Given that the estimate of the autocorrelation coefficient in the investment wedge lies at the boundary, it was kept fixed at its estimated value when computing the bootstrapped estimates of other model parameters.
} 
Table 5: Variance Decompositions

\begin{tabular}{lcccc}
\hline \hline \multicolumn{1}{c}{$\mathbf{C}$} & $\mathbf{H}$ & $\mathbf{Y}$ & $\mathbf{I}$ \\
Baseline & & & & \\
\hline \hline \% var from $\mu_{t}$ & $\begin{array}{c}0.48 \\
(0.36,0.56)\end{array}$ & $\begin{array}{c}0.80 \\
(0.67,0.84)\end{array}$ & $\begin{array}{c}0.94 \\
(0.81,0.96)\end{array}$ & $\begin{array}{c}0.90 \\
(0.76,0.93)\end{array}$ \\
& & & & \\
Separable Preferences & & & \\
\hline \hline \% var from $\mu_{t}$ & $\begin{array}{c}0.08 \\
(0.06,0.10)\end{array}$ & $\begin{array}{c}0.82 \\
(0.69,0.87)\end{array}$ & $\begin{array}{c}0.93 \\
(0.79,0.96)\end{array}$ & $\begin{array}{c}0.94 \\
(0.81,0.96)\end{array}$ \\
Baseline $R B C$ & & & & \\
\hline \hline \% var from $\mu_{t}$ & $\begin{array}{c}0.24 \\
(0.18,0.31)\end{array}$ & $\begin{array}{c}0.21 \\
(0.15,0.25)\end{array}$ & $\begin{array}{c}0.05 \\
(0.04,0.06)\end{array}$ & $\begin{array}{c}0.17 \\
(0.12,0.21)\end{array}$ \\
\hline \hline
\end{tabular}

Remarkably, a single shock explains the bulk of business fluctuations for the post-war U.S. economy. The top row shows the variance decomposition corresponding to the baseline model. Investment shocks explain about $40 \%-50 \%$ of overall consumption variation at business-cycle frequencies; at the same time they account for at least $70 \%$ of business-cycle fluctuations in hours, output and investment. Perhaps not surprisingly, the model with separable preferences, $\omega=1$, does as well in explaining the variance of hours, output and investment but fails to account for fluctuations in consumption, with a maximum share of variance of $10 \%$. This reflects the co-movement problem inherited by models with separable preferences. Finally, in the standard RBC model, investment shocks do not play an important role, confirming a well-known result documented in Hall (1997) and Chari, Kehoe, and McGrattan (2007).

Figure 1 compares the evolution of year-on-year growth in consumption, output, investment and total hours in the data (red dashed line) and in the counterfactual evolution of these series in the model driven by investment shocks only (black solid line). Investment shocks explain most of the decline, and subsequent recovery, in the growth rate of output, investment and total hours. Recessions, delineated by the grey areas, correspond to NBER dating. At the same time, consumption growth is predicted to fall in all recessions; investment shocks also account for a substantial part of the declines in consumption. For example, they explain over one third of the sizable decline in consumption in the current recession. 

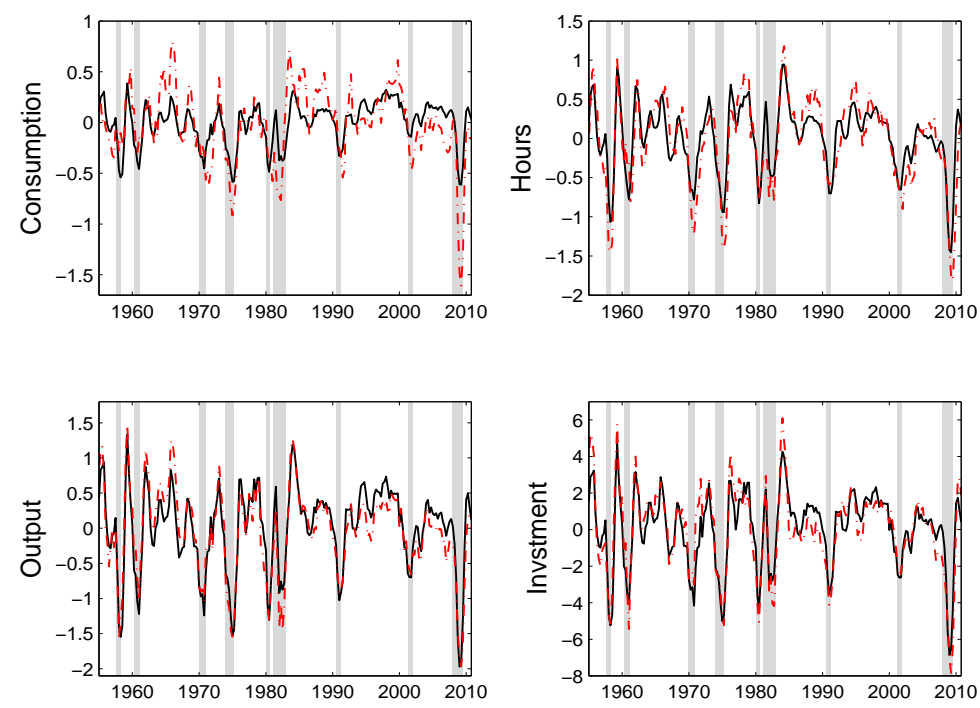

Figure 1: Investment shocks and US business cycles. The figure shows the evolution of consumption, output, investment and hours growth in the data (red dashed line) and in the baseline model with investment shock only (solid black line). Shaded areas denote NBER recessions.

The model's success stems from its ability to capture macroeconomic co-movement. This is also seen by inspecting the labor wedge implied by the three models, displayed in Figure 2. The left-panel shows the labor wedges in deviations from steady-state values, while the right-panel displays the HP detrended wedges. The labor wedge in the baseline model (black solid line) displays remarkably less business-cycle variation compared to the realbusiness-cycle (red dashed line) and separable-preferences (blue dashed line) alternatives. The labor wedge in the model with separable preferences improves somewhat over the realbusiness-cycle model because of the higher labor supply elasticity, but it still fails to account properly for the evolution of consumption. However, even the baseline model retains some countercyclical fluctuations in the labor wedge, largely reflecting the fact that half of consumption fluctuations remain unaccounted for. In addition, it is worth underscoring the model described here is not nested in the class of models considered in Chari, Kehoe, and McGrattan (2007): this explains why the labor wedge does not play as a big role. Finally, the labor wedge embodies significant low-frequency movement. For a possible account of this feature of the data see Shimer (2009). 

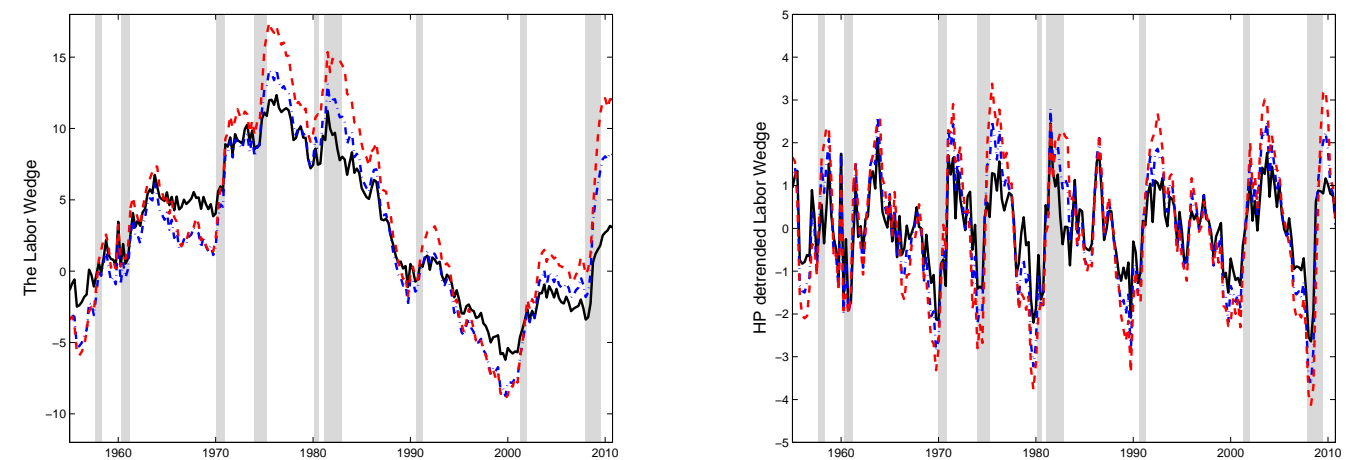

Figure 2: The labor wedge. The figure shows the evolution of the labor wedge for the baseline model (black solid line), the model with separable preferences (blue dashed line) and the RBC model (red dashed line). The left panel displays the labor wedge in percentage deviations from its steady state. The right panel shows the evolution of the HP-detrended labor wedge. The shaded areas denote recessions.

To gain further insight on the propagation mechanism of the model, figures $\mathbf{3}$ and $\mathbf{4}$ show impulse responses to a one percent increase in the investment wedge innovation. Figure 3 contrasts the response of aggregate consumption, output, investment and total hours worked in the three alternative models discussed above. In the standard real-business-cycle model (red dashed line) consumption drops substantially, reflecting the absence of capacity utilization, habit formation and investment-adjustment costs, and the lower elasticity of labor supply. The model with separable preferences (blue dashed line) produces impulse responses for output, hours and investment that are similar to the baseline model (black solid line) and consistent with the behavior of these variables over the business cycle. Consumption increases but its dynamic adjustment is fundamentally different to the baseline model, where aggregate consumption increases together with total hours and investment. This explains the inability of the model with separable preferences to account for business cycles in consumption. In particular the baseline model produces hump-shaped impulse responses for all variables, including, consumption, in line with empirical impulse responses to "investment shocks" in Fisher (2006) and Gilchrist and Zakrajšek (2012). ${ }^{20}$

Figure 4 shows the response of the individual components of consumption (left-panel) and total hours (right-panel). The consumption of both employed and non-employed agents

\footnotetext{
${ }^{20}$ In Fisher (2006) the shock is identified from a measure of the relative price of investment. In Gilchrist and Zakrajšek (2012) it is measured from corporate spreads - see discussion in section 4 above.
} 

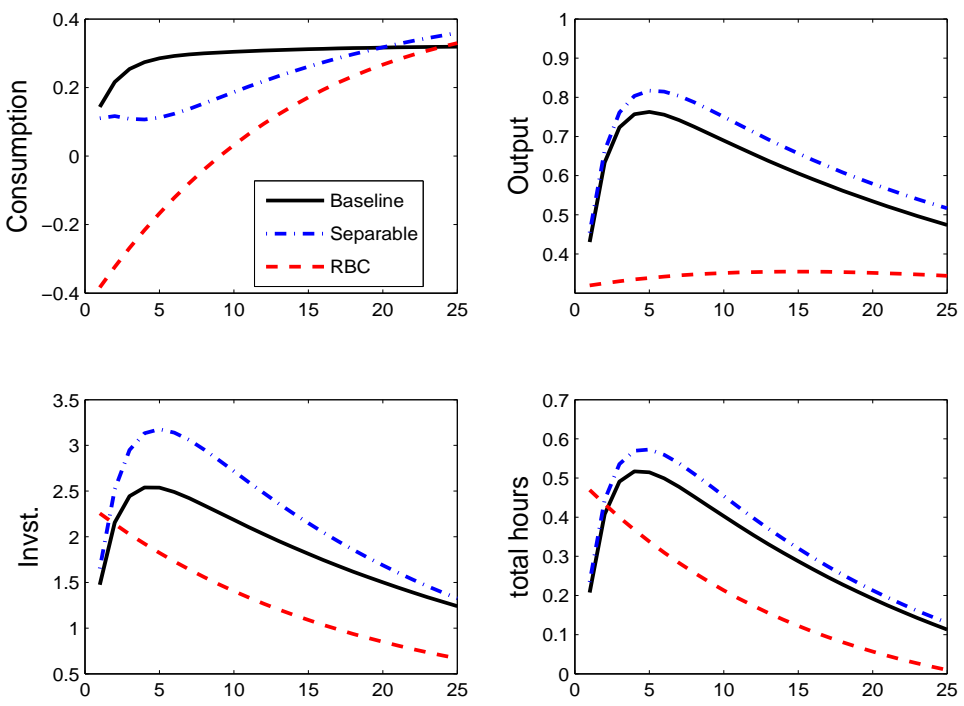

Figure 3: Impulse response to investment. The figure shows the impulse response to a one percent increase in the investment wedge. The solid black line denotes the baseline model, while the dashed blue and red line describe the model with separable preferences and the RBC model respectively.

rises but by significantly less than aggregate consumption, which also depends on the number of employed in the economy. Both employment and individual hours increase in response to an investment shock, with employment explaining roughly two-thirds of the overall increase in total hours.

To summarize, this section establishes shocks to the marginal efficiency of investment to be a quantitatively important source of business fluctuations. The foundation of this empirical relevance is the presence of co-movement: conditional on such disturbances, hours, consumption and investment rise in booms and fall in recessions.

\section{Robustness}

The following section reveals that the central findings are robust to alternative parameter configurations and the adopted identification strategy. As a final exercise we show our model can be mapped into the model of unemployment proposed by Hall (2009). So reinterpreted, use of unemployment data in estimation confirms our benchmark findings. 

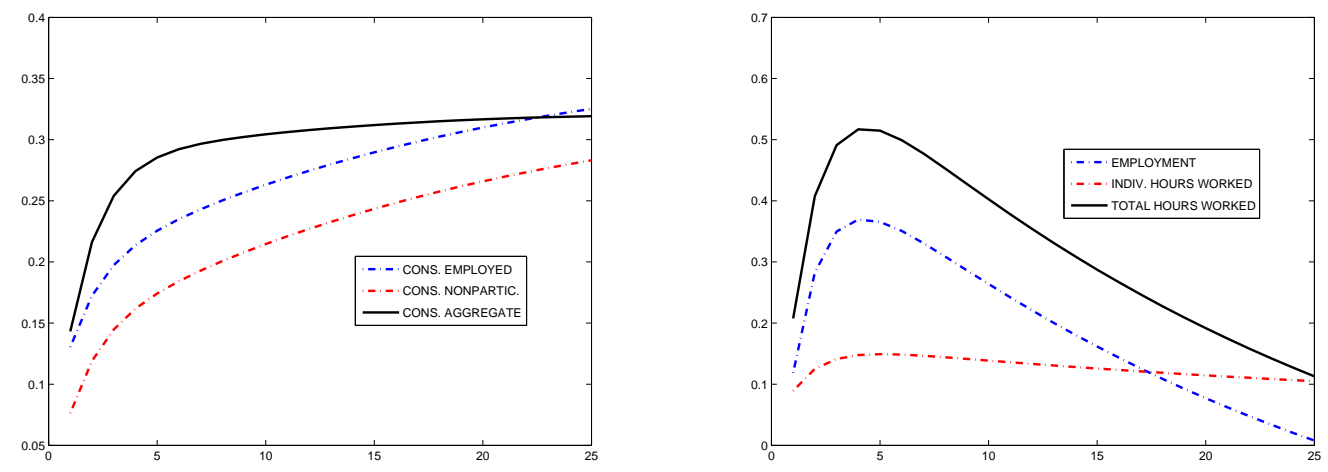

Figure 4: Impulse response in the baseline model: consumption and hours . The figure shows the impulse response to a one percent increase to the investment wedge. The left panel displays the response of aggregate consumption (solid black) and consumption of employed (dashed blue) and non-employed (dashed red). The right panel shows the response of total hours (solid black), employment (dashed blue) and individual hours (dashed red).

\subsection{Co-movement: sensitivity analysis}

To gauge the sensitivity of conclusions to parametric assumptions, we report a distribution of impulse response functions corresponding to economies distinguished by different assumptions on the degree of autocorrelation in the investment wedge, the degree of habit formation and the level of investment-adjustment costs. The following set of parameters are considered: $\rho_{I} \in[0.75 ; 0.99], b \in[0.0 ; 0.6]$ and $\phi_{I} \in[0.0 ; 2.0]$. The persistence of the investment shocks has important implications for the relative magnitude of wealth and substitution effects attached to such shocks, and therefore co-movement. The degree of habit formation was shown in the theory of section 5.2 to assist co-movement, meriting further assessment empirically. And the degree of investment-adjustment costs also affects the degree of substitution between consumption and investment activities, which again bears directly on the question of co-movement.

Figure 5 shows impulse responses to a positive unit innovation to the investment wedge, in the baseline model (left-panels) and the model with separable preferences (right-panels). The top panels show impulse responses of aggregate consumption while the bottom panels display the impulse responses for output. The blue areas correspond to the set of impulse responses obtained allowing different model parameter values to vary. For this set of parameters the model displays positive co-movement in response to an innovation to the investment 

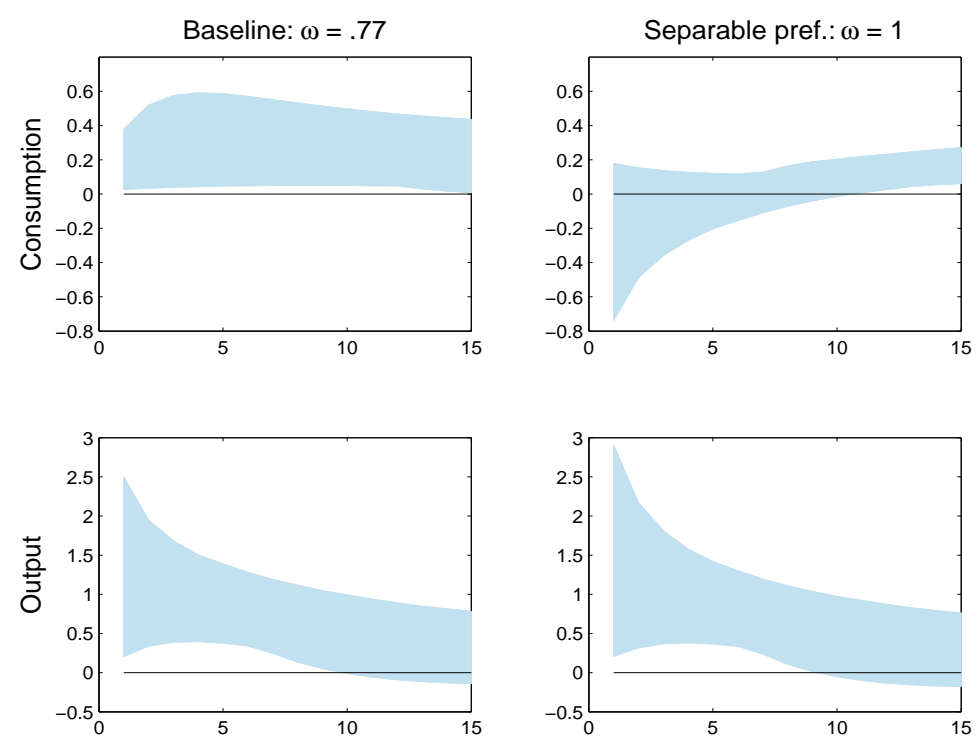

Figure 5: Robustness. The figures displays impulse responses to a one percent increase in the investment wedge. The shaded areas display the set of impulse responses corresponding to alternative model parametrizations.

wedge. In contrast, the model with separable preferences displays a negative response in consumption for many parameter values.

\subsection{Identification}

The identification of the investment wedge process described in section 7.1 reflects the objective to quantify the role of investment shocks over the business cycle. In this section we perform a simple exercise to evaluate whether our specific identification is the main reason for our results. The model is re-estimated after swapping the labor wedge (the other main candidate to explain business cycles) in (15) for the investment wedge - that is, apply the identification strategy to identify innovations to the labor disturbance, rather than the investment disturbance. The bottom row of table 6 shows the labor wedge, while accounting for roughly half of consumption fluctuations and two-thirds of volatility in total hours, fails to account for most business fluctuations in investment and output. This shows that the identification of the wedge per se is not the reason for the success of the baseline model. 
Table 6: Robustness Exercises

\begin{tabular}{|c|c|c|c|c|}
\hline & $\mathrm{C}$ & $\mathbf{H}$ & $\mathbf{Y}$ & I \\
\hline \multicolumn{5}{|c|}{ Model with unemployment as observable $(\ln -L=44.97)$} \\
\hline$\%$ var from $\mu_{t}$ & $\begin{array}{c}0.42 \\
(0.33,0.51)\end{array}$ & $\begin{array}{c}0.87 \\
(0.76,0.91)\end{array}$ & $\begin{array}{c}0.94 \\
(0.83,0.97)\end{array}$ & $\begin{array}{c}0.91 \\
(0.80,0.94)\end{array}$ \\
\hline \multicolumn{5}{|c|}{ Independent labor wedge $(\ln -L=-151.23)$} \\
\hline$\%$ var from $\tau_{t}^{w}$ & $\begin{array}{c}0.46 \\
(0.34,0.57)\end{array}$ & $\begin{array}{c}0.70 \\
(0.57,0.74)\end{array}$ & $\begin{array}{c}0.32 \\
(0.25,0.37)\end{array}$ & $\begin{array}{c}0.20 \\
(0.14,0.24)\end{array}$ \\
\hline
\end{tabular}

\subsection{Hall (2009) model of unemployment}

The baseline model explains movement in total hours with an highly elastic labor supply which reflects households' preferences. Following Hall (2009) the model can be reinterpreted as a theory of unemployment which is the outcome of a search and matching equilibrium between firms and workers. In contrast to that paper, the model here constitutes a completely specified general equilibrium framework, clearly required for the questions answered. The appendix describes this reinterpretation and demonstrates the resulting model equations are the same as in the baseline model with the understanding that non-employment is now unemployment. Consistent with this interpretation, the baseline model is re-estimated with two modifications. First, the variable $e_{t}$ is interpreted as the employment rate (one minus the unemployment rate) with a steady state value of $\bar{e}=0.95$. The model abstracts from the participation margin, consequently one minus the unemployment rate from the Household Survey is used as an observable in the estimation, instead of total hours worked. Second, the elasticity of employment to the wage is reduced to 1.5 to be roughly consistent with the lower volatility of the employment rate - the elasticity is comparable to the value chosen in Hall (2009). This partly reflects the absence of the participation margin, and partly the different behavior of the measured employment rate, compared to the measure of total hours used in the baseline estimation.

To summarize, we replicate the estimation and simulation exercise performed with the baseline model, using unemployment as an observable and the alternative parameter values 
describe above. Remaining model parameters, the data-generating process for the disturbances and the identification of the investment shock is the same as for the baseline model. The top row of table 6 shows the variance explained by the investment shock. Perhaps not surprisingly, the results are very similar to the ones obtained using the baseline specification.

\section{Discussion and Literature}

There has been an extensive literature exploring questions of co-movement. Most recently, there has been considerable interest in models of news shocks, but more generally there has been a range of work focused on co-movement conditional on non-TFP shocks such as exogenous variation in government purchases and various investment disturbances. While it is impossible to do justice to this literature here, the following section draws attention to both some closely related work and also some implications of the framework developed here for these other disturbances.

\subsection{GHH Preferences and Nominal Rigidities}

Jaimovich and Rebelo (2009) propose a preference structure which, in a neoclassical model, generates positive co-movement in response to news shocks. The theory represents a generalization of Greenwood, Hercowitz, and Huffman (1988) ensuring consistency with a balanced growth path. While the focus concerns requirements for co-movement in response to news shocks, the model implies positive co-movement in the case of either investment-specific technology shocks or marginal efficiency of investment shocks. We view our theory as an advancement for two reasons. First, as emphasized by Jaimovich and Rebelo (2009), preference structures based on modification of $\mathrm{GHH}$ preferences require assuming leisure is inferior in the short run. It is not obvious that one would want to make such strong assumptions about the wealth effects on labor supply. While there is considerable debate about whether these wealth effects are small or large, there is very little evidence that they are negative. Second, GHH preferences imply a complementarity between consumption and hours that is considerably higher than under our preference specification, which would be difficult to reconcile with empirical evidence about consumption differentials. ${ }^{21}$

\footnotetext{
${ }^{21}$ See also Monacelli and Perotti (2008).
} 
Other approaches to generate co-movement with standard preference structures also exist. However, they invariably require assuming nominal rigidities and suboptimal monetary policy. Should policy be optimal and implement the flexible price equilibrium, then co-movement would not obtain. As an example Christiano, Motto, and Rostagno (2013) provide compelling evidence on the role of risk shocks in macroeconomic fluctuations. While not disputing the empirical importance of their findings, a key emphasis of their paper is not only the fact that risk shocks explain substantial variation in all macroeconomic series of interest, but they are also consistent with the correct co-movement properties. Despite this, dynamic properties of consumption remain problematic. To correct this negative result the authors emphasize the importance of nominal rigidities and specific assumptions about monetary policy rule to generate positive co-movement.

While it seems plausible that monetary policy is not fully optimal, it does render results sensitive to the precise rule chosen. And small differences in the specification of such rules can alter conclusions about both the fundamental drivers of business cycles and their associated co-movement properties. For example, Christiano, Motto, and Rostagno (2013) demonstrate that including a measure of risk in a standard Taylor rule implies consumption does not exhibit the correct co-movement. Similarly, Sala, Soderstrom, and Trigari (2010) show small changes to the rule specified by Justiniano, Primiceri, and Tambalotti (2011) leads to a diminished role for marginal efficiency of investment shocks.

\subsection{Co-movement: other shocks}

This paper emphasizes the role of shocks to the marginal efficiency of investment. However, the existence of consumption heterogeneity and concomitant compositional effects, has consequences for other classes of disturbance. The following offers some brief commentary further detail and numerical examples can be found in Eusepi and Preston (2009), an earlier draft of this paper.

News shocks. A recent literature models new shocks as signals about future total factor productivity — see, for example, Beaudry and Portier (2007b), Jaimovich and Rebelo (2009) and Schmitt-Grohe and Uribe (2012). Conditions (11) and (12) also govern co-movement in this case. However, the nature of co-movement is fundamentally different: wealth effects dominate substitution effects so that consumption, investment and hours fall on receipt of 
positive news about the state of future technology. Positive wealth effects lead to a fall in employment and therefore aggregate consumption, even though individual consumption of the employed and non-employed rise. Market participants need not work and invest today to capture the benefits of higher TFP tomorrow. As such, the news shock produces only an increase in permanent income. To engineer dynamics consistent with conventional views of the business cycle, requires investment-adjustment costs to induce sufficiently strong substitution effects which increase employment and investment in the current period, thereby generating the "right" co-movement.

Spending shocks. The recent financial crises has restarted the debate about the macroeconomic effects of government spending on economic activity. Ramey (2011a) reviews both the theoretical and empirical literature. ${ }^{22}$ In the standard RBC framework, an increase in government spending induces a less-than-one gross output multiplier because of lack of comovement: negative wealth and substitution effects cause a drop consumption. The simple model described in section 5 , however, can produce output multipliers larger than one. Consider an exogenous component of aggregate demand $G_{t}$, arising from government purchases, that is for simplicity zero in steady state. The resource constraint requires

$$
\hat{G}_{t}=\hat{Y}_{t}-\frac{I}{Y} \hat{I}_{t}-\frac{C}{Y} \hat{C}_{t}
$$

Assuming lump-sum taxation and a balanced budget, the introduction of a disturbance to the resource constraint only affects relation (12). It becomes

$$
\frac{I}{Y} \hat{I}_{t}=\left(1-\alpha-\frac{C}{Y} m_{\omega}\right) \hat{N}_{t}-\hat{G}_{t} .
$$

For a sufficiently low share of consumption from non-employed $\left(\omega<\omega^{*}\right)$ consumption and hours are positively related — see equation (11) — but investment might increase or not, depending on model parameters, since increases in government spending crowd out investment - making co-movement less likely. In general, compared to investment shocks, conditional co-movement to government spending shocks is harder to achieve because both wealth and substitution effects weigh down on consumption.

\footnotetext{
${ }^{22}$ There is now an extensive literature on the consumption response to government expenditure shocks. And evidence on the sign of this relationship fails to speak with unanimous voice. Examples on either side of this debate are Blanchard and Perotti (2002), which suggests positive co-movement based on an identified vector autoregression; and Ramey and Shapiro (1998) and Ramey (2011b) which suggest negative co-movement based on the so-called narrative approach.
} 


\section{Conclusion}

Recent empirical evidence indicates that 'investment' shocks, due to financial frictions, are a key determinant of business cycle fluctuations. The paper shows that a neoclassical model featuring heterogeneity in consumption of employed and nonemployed can generate positive co-movement between consumption, investment and hours in response to shocks to the marginal efficiency of investment. In the model, individual consumption is affected by the number of hours worked as predicted by theories of home production. As a consequence, variation in the employment rate affects aggregate consumption in the same direction through a composition effect. The results suggest heterogeneity might be central to explaining some observed characteristics of macroeconomic dynamics. Importantly, estimation of the model reveals marginal efficiency of investment shocks to be important drivers of business cycles explain some 50 percent of consumption variance and more than 80 percent of variance in investment, hours and output. 


\section{References}

Abel, A. B. (1990): "Asset Prices under Habit Formation and Catching up with the Jonses," American Economic Review Papers and Proceedings, 90, 38-42.

Aguiar, M., and E. Hurst (2005): "Consumption versus Expenditure," Journal of Political Economy, 113(5), 919-948.

— (2008): "Deconstructing Lifecycle Expenditure," manuscript, Univeristy of Chicago.

Aguiar, M. A., E. Hurst, and L. Karabarbounis (2011): "Time Use During Recessions," NBER Working Papers 17259, National Bureau of Economic Research, Inc.

Attanasio, O., and S. J. Davis (1996): "Relative Wage Movements and the Distribution of Consumption," Journal of Political Economy, 104(6), 1227-62.

Barro, R. J., and R. G. King (1984): "Time-separable Preferences and IntertemporalSubstitution Models of Business Cycles," The Quarterly Journal of Economics, 99(4), 817-39.

BAsu, S., And B. Bundick (2012): "Uncertainty Shocks in a Model of Effective Demand," Nber working papers, National Bureau of Economic Research, Inc.

Beaudry, P., And F. Portier (2007a): "When Can Changes in Expectations Cause Business Cycle Fluctuations in Neo-Classical Settings?," Journal of Economic Theory, $135,458-477$.

- (2007b): "When can changes in expectations cause business cycle fluctuations in neo-classical settings?," Journal of Economic Theory, 135(1), 458-477.

Becker, G. S. (1965): "A Theory of the Allocation of Time," The Economic Journal, $75(299), 493-517$.

Bernanke, B. S., M. Gertler, and S. Gilchrist (1999): "The financial accelerator in a quantitative business cycle framework," in Handbook of Macroeconomics, ed. by J. B. Taylor, and M. Woodford, vol. 1 of Handbook of Macroeconomics, chap. 21, pp. 1341-1393. Elsevier. 
Bilbite, F. O. (2009): "Nonseparable Preferences, Fiscal Policy Puzzles, and Inferior Goods," Journal of Money, Credit and Banking, 41(2-3), 443-450.

(2011): "Nonseparable Preferences, Frisch Labor Supply, and the Consumption Multiplier of Government Spending: One Solution to a Fiscal Policy Puzzle," Journal of Money, Credit and Banking, 43(1), 221-251.

Blanchard, O., and R. Perotti (2002): "An Empirical Characterization Of The Dynamic Effects Of Changes In Government Spending And Taxes On Output," The Quarterly Journal of Economics, 117(4), 1329-1368.

Bloom, N. (2009): "The Impact of Uncertainty Shocks," Econometrica, 77(3), 623-685.

Blundell, R., L. Pistaferri, and I. Preston (2008): "Consumption Inequality and Partial Insurance," American Economic Review, 98(5), 1887-1921.

Campbell, J. Y. (1994): "Inspecting the mechanism: An analytical approach to the stochastic growth model," Journal of Monetary Economics, 33(3), 463-506.

Carlstrom, C. T., and T. S. Fuerst (1997): "Agency Cost, Net Worth, and Business Cycle Fluctuations: A Computable General Equilibrium Analysis," American Economic Review, 87(5), 893-910.

Chari, V., P. J. Kehoe, and E. R. McGrattan (2007): "Business Cycle Accounting," Econometrica, 75(3), 781-836.

Cho, J.-O., And T. F. Cooley (1994): "Employment and hours over the business cycle," Journal of Economic Dynamics and Control, 18(2), 411 - 432.

Christiano, L., R. Motto, and M. Rostagno (2013): "Risk Shocks," Nber working papers, National Bureau of Economic Research, Inc.

Christiano, L. J., And J. M. Davis (2006): "Two Flaws In Business Cycle Accounting," NBER Working Papers 12647, National Bureau of Economic Research, Inc.

Cummins, J. G., and G. L. Violante (2002): "Investment-Specific Technical Change in the US (1947-2000): Measurement and Macroeconomic Consequences," Review of Economic Dynamics, 5(2), 243-284.

Dotsey, M., And R. G. King (2006): "Pricing, Production, and Persistence," Journal of the European Economic Association, 4(5), 893-928. 
Eusepi, S., And B. Preston (2009): "Labor Supply Heterogeneity and Macroeconomic Co-movement," NBER Working Paper no. 15561.

Fisher, J. D. M. (2006): "The Dynamic Effects of Neutral and Investment-Specific Technology Shocks," Journal of Political Economy, 114(3), 413-451.

Francis, N., And V. A. Ramey (2009): "Measures of per Capita Hours and Their Implications for the Technology-Hours Debate," Journal of Money, Credit and Banking, 41(6), 1071-1097.

Furlanetto, F., And M. Seneca (2010): "Investment-specific technology shocks and consumption," Working paper, Norges Bank.

Gertler, M., L. Sala, And A. Trigari (2008): "An Estimated Monetary DSGE Model with Unemployment and Staggered Nominal Wage Bargaining," Journal of Money, Credit and Banking, 40(8), 1713-1764.

Gilchrist, S., A. Ortiz, and E. Zakrajsek (2009): "Credit Risk and the Macroeconomy" Evidence from an Estimated DSGE Model," manuscript, Boston University.

Gilchrist, S., And E. Zakrajsek (2012): "Credit Spreads and Business Cycle Fluctuations," American Economic Review, 102(4), 1692-1720.

— (forthcoming): "Credit Spreads and Business Cycle Fluctuations," in Rethinking the Financial Crisis, ed. by A. Blinder, A. Lo, and R. Solow. Russell Sage Foundation.

Gourio, F. (2011): “Credit Risk and Disaster Risk," NBER Working Papers 17026, National Bureau of Economic Research, Inc.

Greenwood, J., Z. Hercowitz, and G. W. Huffman (1988): "Investment, Capacity Utilization and the Real Business Cycle," American Economic Review, 78(3), 402-417.

Hagedorn, M., and I. Manovskit (2008): "The Cyclical Behavior of Equilibrium Unemployment and Vacancies Revisited," American Economic Review, 98(4), 1692-1706.

Hall, R. (1997): "Macroeconomic Fluctuations and the Allocation of Time," Journal of Labor Economics, 15(1), 223-250.

(2009): "Reconciling Cyclical Movements in the Marginal Value of Time and the Marginal Product of Labor," Journal of Political Economy, 117(2), 281-323. 
HALl, R. E. (2005): "Employment Fluctuations with Equilibrium Wage Stickiness," American Economic Review, 95(1), 50-65.

(2011): "The High Sensitivity of Economic Activity to Financial Frictions," Economic Journal, 121(552), 351-378.

Hansen, G. (1985): "Indivisible Labor and the Business Cycle," Journal of Monetary Economics, 16, 309-337.

Heathcote, J., F. Perri, and G. L. Violante (2010): "Unequal We Stand: An Empirical Analysis of Economic Inequality in the United States: 1967-2006," Review of Economic Dynamics, 13(1), 15-51.

Heathcote, J., K. Storesletten, and G. L. Violante (2011): "The Macroeconomic Implications of Rising Wage Inequality in the United States," .

Jaimovich, N., and S. Rebelo (2009): "Can News About the Future Drive the Business Cycle?," American Economic Review, 99(4), 1097-1118.

Justiniano, A., G. Primiceri, and A. Tambalotti (2011): "Investment Shocks and the Relative Price of Investment," Review of Economic Dynamics, 14(1), 101-121.

King, R. G., C. I. Plosser, and S. T. Rebelo (1988): "Production, growth and business cycles : I. The basic neoclassical model," Journal of Monetary Economics, 21(2-3), $195-232$.

Kydland, F. E., and E. C. Prescott (1982): "Time to Build and Aggregate Fluctuations," Econometrica, 50(6), 1345-1370.

Monacelli, T., and R. Perotti (2008): "Fiscal Policy, Wealth Effects, and Markups," unpublished, Universita Bocconi.

Ramey, V. A. (2011a): "Can Government Purchases Stimulate the Economy?," Journal of Economic Literature, 49(3), 673-85.

_ (2011b): "Identifying Government Spending Shocks: It's all in the Timing," The Quarterly Journal of Economics, 126(1), 1-50.

Ramey, V. A., And M. D. Shapiro (1998): "Costly capital reallocation and the effects of government spending," Carnegie-Rochester Conference Series on Public Policy, 48(1), $145-194$. 
Ravina, E. (2011): "Habit Persistence and Keeping Up with the Joneses:Evidence from Micro Data," NYU Working Paper FIN-05-046, Columbia University.

Rogerson, R. (1988): "Indivisible labor, lotteries and equilibrium," Journal of Monetary Economics, 21(1), 3-16.

Sala, L., U. Soderstrom, And A. Trigari (2010): "The Output Gap, the Labor Wedge, and the Dynamic Behavior of Hours," Discussion paper.

Schmitt-Grohe, S., And M. Uribe (2012): "What's News in Business Cycles," Econometrica, 80, 2733-2764.

Shimer, R. (2005): "The Cyclical Behavior of Equilibrium Unemployment and Vacancies," American Economic Review, 95(1), 25-49.

(2009): "Convergence in Macroeconomics: The Labor Wedge," American Economic Journal: Macroeconomics, 1(1), 280-97.

Trabandt, M., and H. Uhlig (2009): "How Far Are We From The Slippery Slope? The Laffer Curve Revisited," Nber working papers, National Bureau of Economic Research, Inc.

(2012): "How do Laffer Curves Differ Across Countries?," NBER Working Papers 17862.

URIBE, M., And V. Z. Yue (2006): "Country spreads and emerging countries: Who drives whom?," Journal of International Economics, 69(1), 6-36. 


\section{A Appendix (not for publication)}

\section{A.1 First-order conditions}

Risk sharing. The first-order conditions with respect to consumption in the two groups gives

$$
\left(C_{t}^{e}-b C_{t-1}\right)^{-\sigma}\left(1+(\sigma-1) \kappa n_{t}^{1+\phi_{n}^{-1}}\right)^{\sigma}=\Lambda_{t}
$$

and

$$
\left(C_{t}^{n e}-b C_{t-1}\right)^{-\sigma}=\Lambda_{t}
$$

where $\Lambda_{t}$ is the Lagrange multiplier on the budget constraint. Together they imply the risk-sharing condition

$$
\frac{C_{t}^{e}-b C_{t-1}}{C_{t}^{n e}-b C_{t-1}}=1+(\sigma-1) \kappa n_{t}^{1+\phi_{n}^{-1}}
$$

so that employed members enjoy more consumption to be compensated for work effort.

Labor supply. The first-order condition with respect to the employment rate gives

$$
\begin{aligned}
& \frac{1}{1-\sigma}\left[\left(C_{t}^{n e}-b C_{t-1}\right)^{1-\sigma}-\left(C_{t}^{e}-b C_{t-1}\right)^{1-\sigma}\left(1+(\sigma-1) \kappa n_{t}^{1+\phi_{n}^{-1}}\right)^{\sigma}\right] \\
& =\Lambda_{t}\left[\left(1-\tau_{w, t}\right) W_{t} n_{t}-C_{t}^{e}+C_{t}^{n e}\right]-X_{t}^{1-\sigma} \Phi_{e}\left(e_{t}\right)
\end{aligned}
$$

which, substituting for $\Lambda_{t}$ in terms of the marginal utilities, can be re-arranged as

$$
\frac{\sigma}{\sigma-1}\left(C_{t}^{e}-C_{t}^{n e}\right)=\left(1-\tau_{w, t}\right) W_{t} n_{t}-\frac{\Phi_{e}\left(e_{t}\right)}{X_{t}^{\sigma-1} \Lambda_{t}}
$$

The first-order condition with respect to hours (of the employed) gives

$$
\frac{C_{t}^{e}-b C_{t-1}}{\sigma-1}=\frac{1+(\sigma-1) \kappa n_{t}^{1+\phi_{n}^{-1}}}{\sigma(\sigma-1) \kappa\left(1+\phi_{n}^{-1}\right) n_{t}^{\phi_{n}^{-1}}}\left(1-\tau_{w, t}\right) W_{t}
$$

Supply of capital services. The capital Euler equation is

$$
E_{t}\left\{\frac{\Lambda_{t+1}}{\Xi_{t}} R_{t+1}^{K} U_{t+1}+\frac{\Xi_{t+1}}{\Xi_{t}}\left[1-\delta\left(U_{t+1}\right)\right]\right\}=\beta^{-1}
$$

where $\Xi_{t}$ the the multiplier associated with the capital accumulation equation. Investment dynamics obey

$$
\Lambda_{t}=\mu_{t} \Xi_{t}\left[1-\phi\left(\frac{I_{t}}{I_{t-1}}\right)-\frac{I_{t}}{I_{t-1}} \phi^{\prime}\left(\frac{I_{t}}{I_{t-1}}\right)\right]+\beta E_{t}\left[\Xi_{t+1} \mu_{t+1}\left(\frac{I_{t+1}}{I_{t}}\right)^{2} \phi^{\prime}\left(\frac{I_{t+1}}{I_{t}}\right)\right] .
$$


Finally, capacity utilization is determined by

$$
\Lambda_{t} R_{t}^{K}=\Xi_{t} \delta^{\prime}\left(U_{t}\right)
$$

Firms. Output is produced by perfectly competitive firms with the Cobb-Douglas production function

$$
Y_{t}=\left(U_{t} K_{t}\right)^{\alpha} N_{t}^{1-\alpha} .
$$

Firm demand for labor and capital services is then

$$
R_{t}^{K}=\alpha \frac{Y_{t}}{U_{t} K_{t}}
$$

and

$$
W_{t}=(1-\alpha) \frac{Y_{t}}{N_{t}} .
$$

Resource constraint. The flow budget constraint of the household is

$$
C_{t}+I_{t}=R_{t}^{K} U_{t} K_{t}+\left(1-\tau_{w, t}\right) W_{t} N_{t}-T_{t} .
$$

Using the following government budget rule

$$
T_{t}=G_{t}-\tau_{w, t} W_{t} N_{t}
$$

yields

$$
C_{t}+I_{t}+G_{t}=Y_{t} .
$$

where

$$
G_{t}=X_{t} g_{t}
$$

\section{A.2 Steady state}

The steady-state value of $\mu_{t}$ is $\bar{\mu}=1$. All non-stationary variables are expressed in efficiency units (normalized by $X_{t}$ as required) and $\bar{\gamma}$ denotes steady-state technology growth. The real interest rate is defined as

$$
\alpha \frac{\bar{y}}{\bar{k}}=\frac{\bar{U} \bar{R}^{k}}{\bar{\gamma}}=\frac{\bar{\gamma}^{\sigma} \beta^{-1}-1+\delta}{\bar{\gamma}},
$$

where $\bar{Z}$ denotes steady-state value for any variable $Z$. From the capital accumulation equation

$$
\frac{\bar{\imath}}{\bar{k}}=1-\frac{1-\delta}{\bar{\gamma}}
$$


In steady state, capacity utilization is pinned down by

$$
\bar{U} \bar{R}^{K}=\delta^{\prime}(\bar{U}) \bar{U}
$$

Assuming the functional form

$$
\delta(U)=\frac{1}{\theta} U^{\theta} ; \delta^{\prime}(\bar{U}) \bar{U}=\bar{U}^{\theta}=\theta \delta
$$

so that

$$
\theta=\frac{\bar{\gamma}^{\sigma} \beta^{-1}-1+\delta}{\delta}
$$

and

$$
\epsilon_{\delta}=\frac{\delta^{\prime \prime}(\bar{U}) \bar{U}}{\delta^{\prime}(\bar{U})}=(\theta-1)
$$

Next, notice that

$$
\frac{\bar{w} \bar{N}}{\bar{c}}=(1-\alpha) \frac{\bar{y}}{\bar{k}}\left(\frac{\bar{c}}{\bar{k}}\right)^{-1}
$$

using

$$
\frac{\bar{c}}{\bar{k}}=\frac{\bar{y}}{\bar{k}}-\frac{\bar{g}}{\bar{y}} \frac{\bar{y}}{\bar{k}}-\frac{\bar{\imath}}{\bar{k}}=\left(1-\frac{\bar{g}}{\bar{y}}\right) \frac{\bar{y}}{\bar{k}}-\frac{\bar{\imath}}{\bar{k}} .
$$

From the labor supply first-order condition

$$
\begin{aligned}
\frac{\bar{c}^{e}-b \bar{\gamma}^{-1} \bar{c}}{(\sigma-1)} & =\frac{1+(\sigma-1) \kappa \bar{n}^{1+\phi_{n}^{-1}}}{\sigma(\sigma-1) \kappa\left(1+\phi_{n}^{-1}\right) \bar{n}_{n}^{-1}}\left(1-\bar{\tau}_{w}\right) \bar{w} \\
& =\left[\frac{\nu^{\prime}(\bar{n})}{\nu(\bar{n})}\right]^{-1}\left(1-\bar{\tau}_{w}\right) \bar{w}
\end{aligned}
$$

which, after manipulation, can be rewritten as

$$
\frac{\nu^{\prime}(\bar{n})}{\nu(\bar{n})}=\frac{(\sigma-1) \psi}{s_{e}-\bar{e} b \bar{\gamma}^{-1}}
$$

where we define

$$
\psi=\frac{\left(1-\bar{\tau}_{w}\right) \bar{n} \bar{e} \bar{w}}{\bar{c}} .
$$

From the first-order condition for employment

$$
\frac{\sigma}{\sigma-1}\left(\bar{c}^{e}-\bar{c}^{n e}\right)=\left(1-\bar{\tau}_{w}\right) \bar{w} \bar{n}-\bar{\lambda}^{-1} \Phi_{e}(\bar{e}) .
$$

Define $\omega=\bar{c}^{u} / \bar{c}^{e}$. Dividing by steady-state consumption and re-arranging

$$
\bar{\lambda}^{-1} \frac{\Phi_{e}(\bar{e}) \bar{e}}{\bar{c}}+\frac{\sigma}{\sigma-1}(1-\omega) s_{e}=\psi
$$


where

$$
s_{e}=\bar{c}^{e} \bar{e} / \bar{C}=\frac{1}{1+\left(\bar{e}^{-1}-1\right) \omega} .
$$

The parameter $\bar{\lambda}^{-1} \frac{\Phi_{e}(\bar{e}) \bar{e}}{\bar{c}}$ measures the marginal cost of participation in terms of consumption units (as a fraction of total consumption). We can express it as a fraction $\zeta$ of wage earnings (after tax)

$$
\bar{\lambda}^{-1} \frac{\Phi_{e}(\bar{e}) \bar{e}}{\bar{c}}=\frac{\zeta\left(1-\bar{\tau}_{w}\right) \bar{w} \bar{N}}{\bar{c}}=\zeta \psi .
$$

Risk sharing between employed and nonemployed gives

$$
\frac{\bar{c}^{e} \bar{e}-\bar{e} b \bar{\gamma}^{-1} \bar{c}}{\bar{c}^{n e} \bar{e}-\bar{e} b \bar{\gamma}^{-1} \bar{c}}=\frac{s_{e}-\bar{e} b \bar{\gamma}^{-1}}{\omega s_{e}-\bar{e} b \bar{\gamma}^{-1}}=1+(\sigma-1) \kappa \bar{n}^{1+\phi_{n}^{-1}}
$$

which converges to 1 as $\sigma$ converges to 1 . For a given level of $\bar{n}$ and the other structural parameters this expression gives the value of $\kappa$ as

$$
\kappa=\frac{1}{(\sigma-1) \bar{n}^{1+\phi_{n}^{-1}}} \frac{(1-\omega) s_{e}}{\omega s_{e}-\bar{e} b \bar{\gamma}^{-1}} .
$$

Finally, given $\zeta$, the steady-state labor participation decision relates $\sigma$ to $\omega$ :

$$
\frac{\sigma}{\sigma-1}(1-\omega) s_{e}=(1-\zeta) \psi
$$

Given assumed values for $\bar{n}, \phi_{n}, \kappa$ and $\omega$ the parameters $\sigma$ and $\zeta$ can be found as the solution to the previous equation and

$$
(\sigma-1)\left(1+\phi_{n}^{-1}\right)\left[\left(\sigma \kappa \bar{n}^{1+\phi_{n}^{-1}}\right)^{-1}+\frac{(\sigma-1)}{\sigma}\right]^{-1}=\frac{(\sigma-1) \psi}{s_{e}-\bar{e} b \bar{\gamma}^{-1}}
$$

Substituting for $\kappa$ in the second expression gives

$$
\frac{\sigma}{\sigma-1}(1-\omega) s_{e}=\frac{\psi}{1+\phi_{n}^{-1}}
$$

which combed with (28) implies

$$
\zeta=1-\frac{1}{1+\phi_{n}^{-1}}
$$

Hence, given $\omega$ and $\phi_{n}^{-1}$, we find the corresponding value of

$$
\sigma=\frac{1-\zeta}{1-\zeta-(1-\omega) \psi^{-1} s_{e}}
$$

where the assumed calibration needs to satisfy $1-\zeta-(1-\omega) \psi^{-1} s_{e}>0$. 


\section{A.3 Log-Linear Equations}

Recall that

$$
\nu(n)=\left(1+(\sigma-1) \kappa n^{1+\phi_{n}^{-1}}\right)^{\sigma}
$$

so that

$$
\begin{aligned}
\frac{\nu^{\prime}(n) n}{\nu(n)} & =(\sigma-1)\left(1+\phi_{n}^{-1}\right)\left[\left(\sigma \kappa n^{1+\phi_{n}^{-1}}\right)^{-1}+\frac{(\sigma-1)}{\sigma}\right]^{-1} \\
\frac{\nu^{\prime \prime}(n) n}{\nu^{\prime}(n)} & =\phi_{n}^{-1}+\frac{(\sigma-1)}{\sigma} \frac{\nu^{\prime}(n) n}{\nu(n)} .
\end{aligned}
$$

Consumption and labor supply. Re-expressing (21) in terms of stationary variables and log-linearizing gives

$$
\frac{(\sigma-1)}{s_{e}-\bar{e} b \bar{\gamma}^{-1}}\left[-s_{e} \hat{c}_{t}^{e}-b \bar{\gamma}^{-1} \bar{e}\left(\hat{\gamma}_{t}-\hat{c}_{t-1}\right)\right]+\left(\frac{\nu^{\prime \prime}(\bar{n}) \bar{n}}{\nu^{\prime}(\bar{n})}\right) \hat{n}_{t}=\hat{\lambda}_{t}+\hat{w}_{t}^{a f t a x}
$$

Combining with

$$
\frac{1}{s_{e}-b \bar{\gamma}^{-1} \bar{e}}\left[-s_{e} \hat{c}_{t}^{e}-b \bar{e} \bar{\gamma}^{-1}\left(\hat{\gamma}_{t}-\hat{c}_{t-1}\right)+\frac{(\sigma-1)}{\sigma} \psi \hat{n}_{t}\right]=\sigma^{-1} \hat{\lambda}_{t},
$$

obtained by log-linearization of (16) in stationary terms, gives individual labor supply

$$
\begin{aligned}
\phi_{n}^{-1} \hat{n}_{t} & =\hat{w}_{t}^{a f t a x}+\sigma^{-1} \hat{\lambda}_{t}, \text { or } \\
\phi_{n}^{-1} \hat{n}_{t} & =\hat{w}_{t}-\tilde{\tau}_{w, t}+\sigma^{-1} \hat{\lambda}_{t}
\end{aligned}
$$

where

$$
\begin{aligned}
w_{t}^{\text {aftax }} & =\left(1-\tau_{w, t}\right) w_{t} \\
\hat{w}_{t}^{\text {aftax }} & =\hat{w}_{t}-\frac{\bar{\tau}^{w}}{1-\bar{\tau}^{w}} \hat{\tau}_{t}^{w}=\hat{w}_{t}-\tilde{\tau}_{w, t} \\
\tilde{\tau}_{w, t} & =\frac{\bar{\tau}^{w}}{1-\bar{\tau}^{w}} \hat{\tau}_{t}^{w}
\end{aligned}
$$

Log-linearizing (20) gives

$$
\frac{\sigma}{\sigma-1}\left(\hat{c}_{t}^{e}-\omega \hat{c}_{t}^{n e}\right) s_{e}=\psi\left(\hat{w}_{t}^{a f t a x}+\hat{n}_{t}\right)-\epsilon_{e} \zeta \psi \hat{e}_{t}+\zeta \psi \hat{\lambda}_{t}
$$

where

$$
\epsilon_{e}=\frac{\Phi^{\prime \prime}(\bar{e}) \bar{e}}{\Phi^{\prime}(\bar{e})}
$$


Combined with the log-linearized marginal utility of employed (31) and nonemployed

$$
\frac{1}{\omega s_{e}-b \bar{\gamma}^{-1} \bar{e}}\left[-\omega s_{e} \hat{c}_{t}^{n e}-b \bar{e} \bar{\gamma}^{-1}\left(\hat{\gamma}_{t}-\hat{c}_{t-1}\right)\right]=\sigma^{-1} \hat{\lambda}_{t}
$$

gives the Frisch employment supply function

$$
\phi_{e}^{-1} \hat{e}_{t}=\hat{w}_{t}-\tilde{\tau}_{w, t}+\left[1-\frac{1}{\psi} \frac{(1-\omega)}{1+\left(\bar{e}^{-1}-1\right) \omega}\right] \hat{\lambda}_{t}
$$

where $\phi_{e}=\left(\epsilon_{e} \zeta\right)^{-1}$ denotes the Frisch elasticity of employment.

Supply of capital services. Log-linearization of the capital Euler equation yields

$$
\hat{\xi}_{t}=E_{t}\left[\left(1-\beta \bar{\gamma}^{-\sigma}(1-\delta)\right) \hat{\lambda}_{t+1}+\left(1-\beta \bar{\gamma}^{-\sigma}(1-\delta)\right) \hat{R}_{t+1}^{K}+\beta \bar{\gamma}^{-\sigma}(1-\delta) \hat{\xi}_{t+1}-\sigma \hat{\gamma}_{t+1}\right]
$$

while investment dynamics in log-linear form is

$$
\hat{\lambda}_{t}-\hat{\xi}_{t}-\hat{\mu}_{t}=-\bar{\gamma}^{2} \phi^{\prime \prime}\left(\hat{\gamma}_{t}+\hat{\imath}_{t}-\hat{\imath}_{t-1}\right)+\beta \bar{\gamma}^{1-\sigma} \bar{\gamma}^{2} \phi^{\prime \prime} E_{t}\left(\hat{\gamma}_{t+1}+\hat{\imath}_{t+1}-\hat{\imath}_{t}\right)
$$

Finally, log-linearizing the capacity utilization equation we get

$$
\hat{R}_{t}^{K}=\epsilon_{\delta} \hat{U}_{t}-\hat{\lambda}_{t}+\hat{\xi}_{t}
$$

where, again,

$$
\epsilon_{\delta}=\frac{\delta^{\prime \prime}(\bar{U}) \bar{U}}{\delta^{\prime}(\bar{U})}=(\theta-1) .
$$

Log-linear model. Summing up the model consists of the following equations:

Marginal utilities of consumption:

$$
\begin{gathered}
\frac{1}{\omega s_{e}-b \bar{\gamma}^{-1} \bar{e}}\left[-\omega s_{e} \hat{c}_{t}^{n e}-b \bar{e} \bar{\gamma}^{-1}\left(\hat{\gamma}_{t}-\hat{c}_{t-1}\right)\right]=\sigma^{-1} \hat{\lambda}_{t} \\
\frac{1}{s_{e}-b \bar{\gamma}^{-1} \bar{e}}\left[-s_{e} \hat{c}_{t}^{e}-b \bar{e} \bar{\gamma}^{-1}\left(\hat{\gamma}_{t}-\hat{c}_{t-1}\right)+\frac{(\sigma-1)}{\sigma} \psi \hat{n}_{t}\right]=\sigma^{-1} \hat{\lambda}_{t}
\end{gathered}
$$

Labor supply:

$$
\begin{gathered}
\phi_{n}^{-1} \hat{n}_{t}=\hat{w}_{t}-\tilde{\tau}_{w, t}+\sigma^{-1} \hat{\lambda}_{t} \\
\phi_{e}^{-1} \hat{e}_{t}=\hat{w}_{t}-\tilde{\tau}_{w, t}+\left[1-\frac{1}{\psi} \frac{(1-\omega)}{1+\left(\bar{e}^{-1}-1\right) \omega}\right] \hat{\lambda}_{t}
\end{gathered}
$$


Euler equations:

$$
\begin{gathered}
\hat{\xi}_{t}=E_{t}\left[\left(1-\beta \bar{\gamma}^{-\sigma}(1-\delta)\right) \hat{\lambda}_{t+1}+\left(1-\beta \bar{\gamma}^{-\sigma}(1-\delta)\right) \hat{R}_{t+1}^{K}+\beta \bar{\gamma}^{-\sigma}(1-\delta) \hat{\xi}_{t+1}-\sigma \hat{\gamma}_{t+1}\right] \\
\hat{\lambda}_{t}-\hat{\xi}_{t}-\hat{\mu}_{t}=-\bar{\gamma}^{2} \phi^{\prime \prime}\left(\hat{\gamma}_{t}+\hat{\imath}_{t}-\hat{\imath}_{t-1}\right)+\beta \bar{\gamma}^{1-\sigma} \bar{\gamma}^{2} \phi^{\prime \prime} E_{t}\left(\hat{\gamma}_{t+1}+\hat{\imath}_{t+1}-\hat{\imath}_{t}\right)
\end{gathered}
$$

Capacity utilization:

$$
\hat{R}_{t}^{K}=\epsilon_{\delta} \hat{U}_{t}-\hat{\lambda}_{t}+\hat{\xi}_{t}
$$

Factors demand:

$$
\begin{gathered}
\hat{W}_{t}=\hat{Y}_{t}-\hat{N}_{t}, \\
\hat{R}_{t}^{K}=\hat{y}_{t}-\hat{U}_{t}-\hat{k}_{t}+\hat{\gamma}_{t} .
\end{gathered}
$$

Output:

$$
\hat{Y}_{t}=-\alpha \hat{\gamma}_{t}+\alpha \hat{U}_{t}+\alpha \hat{k}_{t}+(1-\alpha) \hat{N}_{t}
$$

Resource constraint:

$$
\frac{\bar{v}}{\bar{y}} \hat{t}_{t}+\frac{\bar{c}}{\bar{y}} \hat{c}_{t}+\frac{\bar{g}}{\bar{y}} \hat{g}_{t}=\hat{y}_{t}
$$

Capital accumulation:

$$
\bar{\gamma} \hat{k}_{t+1}=\bar{\gamma} \frac{\bar{\imath}}{\bar{k}} \hat{\mu}_{t}+\bar{\gamma} \frac{\bar{\gamma}}{\bar{k}} \hat{\imath}_{t}-(1-\delta) \hat{\gamma}_{t}+(1-\delta) \hat{k}_{t}-\left(\bar{\gamma}^{\sigma} \beta^{-1}-1+\delta\right) \hat{U}_{t}
$$

Aggregate consumption and hours:

$$
\begin{gathered}
\hat{c}_{t}=s_{e} \hat{c}_{t}^{e}+\left(1-s_{e}\right) \hat{c}_{t}^{n e}+(1-\omega) s_{e} \hat{e}_{t} \\
\hat{N}_{t}=\hat{e}_{t}+\hat{n}_{t} .
\end{gathered}
$$

Exogenous processes:

$$
\begin{aligned}
& Z_{t}=\left(\begin{array}{llll}
\hat{\gamma}_{t}, & \hat{\tau}_{t}^{w}, & \hat{G}_{t}, \hat{\mu}_{t}
\end{array}\right)^{\prime} \\
& Z_{t}=P Z_{t-1}+V \eta_{t}, \quad \eta_{t} \sim N(0, I) .
\end{aligned}
$$




\section{A.4 Nonseparable utility and the normality of consumption and leisure}

Consider an individual with preferences

$$
U\left(c_{t}, l_{t}\right)=\frac{\left(c_{t}-b C_{t-1}\right)^{1-\sigma} \nu\left(1-l_{t}\right)}{1-\sigma}
$$

where $n_{t}=1-l_{t}$ and $l_{t}$ denotes time not spent in market activities and where $\nu(n)$ is defined above. The individual budget constraint can be expressed as

$$
c_{t}+l_{t} W_{t}=M_{t}
$$

where $M_{t}$ denotes non-labor income. Let

$$
\epsilon_{\nu}=\frac{\nu^{\prime \prime}(\bar{n}) \bar{n}}{\nu^{\prime}(\bar{n})}
$$

define the curvature of $\nu(\cdot)$ at steady state. The following Lemma states the required restriction on utility that guarantees concavity.

Lemma 4 Assume $\epsilon_{\nu}$ satisfies the restriction

$$
\epsilon_{\nu}>\frac{(\sigma-1)^{2}}{\sigma} \frac{\psi}{s_{e}-\bar{e} b \bar{\gamma}^{-1}},
$$

then the utility function (36) is concave.

Proof. Let us consider (36) in terms of consumption and leisure. Then we have

$$
U_{l}=-\frac{(c-b C)^{1-\sigma}}{1-\sigma} \nu^{\prime}(1-l)>0
$$

where $U_{x}$ denoted the marginal utility with respect to the argument $x$, and where $\nu^{\prime}(\cdot)$ denotes the derivative of $\nu(\cdot)$ with respect to hours worked. Similarly

$$
U_{l l}=\frac{(c-b C)^{1-\sigma}}{1-\sigma} \nu^{\prime \prime}(1-l)<0
$$

It is straightforward to show that $U_{c}>0$ and $U_{c c}<0$. Further, concavity requires

$$
U_{c c} \cdot U_{l l}-\left(U_{c l}\right)^{2} \geq 0
$$

Substituting for the actual expressions we get

$$
\frac{\sigma}{\sigma-1} \nu(n) \nu^{\prime \prime}(n)(c-b C)^{-2 \sigma}-(c-b C)^{-2 \sigma} \nu^{\prime}(n)^{2}
$$


which on simplifying yields

$$
(c-b C)^{-2 \sigma} \frac{\nu(n)}{n} \nu^{\prime}(n)\left[\frac{\sigma}{\sigma-1} \frac{\nu^{\prime \prime}(n) n}{\nu^{\prime}(n)}-\frac{\nu^{\prime}(n) n}{\nu(n)}\right] .
$$

Noting that at steady state

$$
\frac{\nu^{\prime}(\bar{n}) \bar{n}}{\nu(\bar{n})}=\frac{\left(1-\bar{\tau}^{w}\right) \bar{W} \bar{n}}{\bar{c}^{e}-b \bar{c}}(\sigma-1)=\frac{(\sigma-1) \psi}{s_{e}-\bar{e} b}
$$

where for simplicity we assume no growth, concavity requires

$$
\left[\epsilon_{\nu}-\frac{\psi}{s_{e}-\bar{e} b} s_{e}^{-1} \frac{(\sigma-1)^{2}}{\sigma}\right] \geq 0
$$

The next Lemma states the restrictions required for both consumption and leisure to be normal goods.

Lemma 5 Consumption and leisure are normal goods iff

$$
\epsilon_{\nu}>\frac{(\sigma-1) \psi}{s_{e}-\bar{e} b}
$$

Violation of the above condition implies that consumption is an inferior good.

Proof. Consider the first-order conditions of the static utility maximization in (36) and (37). Total differentiation of the first-order conditions and budget constraint gives

$$
\begin{aligned}
\left(W U_{c c}-U_{c l}\right) \frac{\partial c}{\partial M}+\left(W U_{C l}-U_{l l}\right) \frac{\partial l}{\partial M} & =0 \\
\frac{\partial c}{\partial M}+W \frac{\partial l}{\partial M} & =1
\end{aligned}
$$

where $W$ is kept constant and $M$ denotes non-wage income. We have

$$
\begin{aligned}
\frac{\partial c}{\partial M} & =\left[1-W \frac{U_{c l}-W U_{c c}}{U_{l l}-W U_{c l}}\right]^{-1} \\
& =\left[\left(1-\frac{U_{l}}{U_{c}} \frac{\frac{U_{c l}}{U_{l}}-\frac{U_{c c}}{U_{c l}}}{U_{l}-\frac{U_{c l}}{U_{c}}}\right)^{-1}\right] .
\end{aligned}
$$

Substituting for the chosen utility and using the steady-state restrictions described above yields 


$$
\frac{\partial c}{\partial M}=\left[1+\frac{\psi}{s_{e}-\bar{e} b}\left(\epsilon_{\nu}-\frac{(\sigma-1) \psi}{s_{e}-\bar{e} b}\right)^{-1}\right]^{-1}
$$

which states that consumption is an inferior good if and only if

$$
-\frac{\psi}{s_{e}-\bar{e} b}<\epsilon_{\nu}-\frac{(\sigma-1) \psi}{s_{e}-\bar{e} b}<0
$$

The condition to have both consumption and leisure normal goods is

$$
\frac{U_{c l} / U_{l}-U_{c c} / U_{c}}{U_{l l} U_{l}-U_{c l} / U_{c}}<0 .
$$

Substituting for our chosen functional forms gives

$$
\frac{n}{c-b C} \frac{1}{-\epsilon_{\nu}+\frac{(\sigma-1) \psi}{s_{e}-\bar{e} b}}<0
$$

if and only if

$$
\epsilon_{\nu}>\frac{(\sigma-1) \psi}{s_{e}-\bar{e} b}
$$

Recall from above that for the preferences used in the paper

$$
\frac{\nu^{\prime \prime}(n) n}{\nu^{\prime}(n)}=\phi_{n}^{-1}+\frac{(\sigma-1)}{\sigma} \frac{\nu^{\prime}(n) n}{\nu(n)} .
$$

From the above results the utility function is concave. Normality of both consumption and leisure requires

$$
\frac{\nu^{\prime \prime}(n) n}{\nu^{\prime}(n)}>\frac{\nu^{\prime}(n) n}{\nu(n)}
$$

Now

$$
\phi_{n}^{-1}+\frac{(\sigma-1)}{\sigma} \frac{\nu^{\prime}(n) n}{\nu(n)}>\frac{\nu^{\prime}(n) n}{\nu(n)}
$$

implying the threshold value of $\bar{\phi}_{n}$ is

$$
\begin{aligned}
\bar{\phi}_{n}^{-1} & =\left[1-\frac{(\sigma-1)}{\sigma}\right] \frac{\nu^{\prime}(n) n}{\nu(n)} \\
& =\sigma^{-1} \frac{\nu^{\prime}(n) n}{\nu(n)} .
\end{aligned}
$$

Now use the steady-state restrictions to pin down the parameters of the utility function. As shown above, labor supply restricts $\frac{\nu^{\prime}(n) n}{\nu(n)}$ as follows

$$
\frac{\nu^{\prime}(n) n}{\nu(n)}=\frac{(\sigma-1) \psi}{s_{e}-\bar{e} b \bar{\gamma}^{-1}}
$$


Hence the threshold is

$$
\bar{\phi}_{n}^{-1}=\frac{\left(1-\sigma^{-1}\right) \psi}{s_{e}-\bar{e} b \bar{\gamma}^{-1}}
$$

\section{A.5 Hall (2009) Model}

Define $\eta$ as the vacancy to unemployment ratio. The job finding rate $\phi(\eta)$ is increasing (and concave) in $\eta$. The job destruction rate, $s$, is constant. The unemployment rate, $u_{t}$, evolves according to

$$
u_{t}=\left(1-\phi\left(\eta_{t}\right)\right) u_{t-1}+s\left(1-u_{t-1}\right)
$$

Approximating the dynamics of $u_{t}$ by its stochastic steady state, and defining employment as $e_{t}=1-u_{t}$ gives

$$
e_{t}=\frac{\phi\left(\eta_{t}\right)}{s+\phi\left(\eta_{t}\right)}
$$

which implies that employment is a jump variable. Invert the previous function (so that $\eta$ is a function of $e$ ) giving the job-filling probability

$$
q\left(e_{t}\right)=\frac{\phi\left(\eta\left(e_{t}\right)\right)}{s+\eta\left(e_{t}\right)} .
$$

The production function is

$$
Y_{t}=\left(U_{t} K_{t}\right)^{\alpha}\left(X_{t} e_{t} n_{t}\right)^{1-\alpha}
$$

so that the demand for total hours and capital is the same as in our baseline model. The firm chooses the total amount of hours worked, the amount of effective capital to rent and the number of vacancies to fill. Hall (2009) assumes a specific employment contract between firms and workers. Workers are payed the hourly wage $W_{t}$ : both workers and firms are price takers. In addition, the employment contract requires that firms collect an amount $z_{t}$ from a new worker. Workers and firms bargain over this part of compensation. It is assumed that the bargained payment is a function of $W_{t}$ and the marginal utility of income of the family $\Lambda_{t}$, that is $z_{t}=z\left(W_{t}, \Lambda_{t}\right)$ Firms decide whether to recruit workers, requiring in equilibrium

$$
q\left(e_{t}\right) z_{t}=\chi
$$

where $\chi$ is the cost of holding the vacancy open for a period. This leads to an employment function

$$
e_{t}=\Phi\left(z_{t}\right)
$$


where $\Phi_{z}>0$ as higher payments to the firm (or, in turn lower compensation to the worker) increases employment demand. The family has the same preference structure as described in section 3 of the paper. The family's upper limit on the payment to the employer is defined as

$$
Z_{t}\left(\Lambda_{t}, W_{t}\right)=\frac{1}{1-\sigma} \frac{\left[\left(C_{t}^{e}\right)^{1-\sigma} \nu\left(n_{t}\right)-\left(C_{t}^{u}\right)^{1-\sigma} \nu(0)\right]}{\Lambda_{t}}+\left(1-\tau_{w, t}\right) W_{t} n_{t}-C_{t}^{e}+C_{t}^{u}
$$

which denotes the marginal value from an increase in the employment rate of the family. As before

$$
\nu(n)=\left(1+(\sigma-1) \gamma n^{1+\phi_{n}^{-1}}\right)^{\sigma} .
$$

This term now substitutes the term $\Phi_{e, t}\left(e_{t}\right) / \Lambda_{t}$ in our baseline model, which denotes the marginal cost of participating expressed in terms of income. Given that the minimum payment for the firm is zero, the Nash bargaining up-front payment is

$$
z_{t}=0 \cdot \nu+(1-\nu) Z_{t}\left(\Lambda_{t}, W_{t}\right)
$$

where $\nu$ is the bargaining weight of the job seeker. Substituting the employment function (39) for $z_{t}$ we get

$$
e_{t}=\Phi\left(Z\left(\Lambda_{t}, W_{t}\right)\right)=\Phi^{Z}\left(\Lambda_{t}, W_{t}\right), \text { where } \Phi_{\lambda}^{Z}, \Phi_{w}^{Z}>0
$$

because higher marginal utility of income and higher wages lead to more willingness to work (and thus accepting lower compensation, as the difference between the wage and the up-front payment). The payment from workers to firm captures that actual compensation might be lower than the wage (which measures the marginal product of labor). The model, without addressing the specifics of the contract or the bargaining process, embeds a form of real wage rigidity. In log-linear terms (and after detrending each variables) equation (40) gives the employment function

$$
\hat{e}_{t}=\phi_{e} \hat{w}_{t}+\phi_{e} \phi_{\lambda} \hat{\lambda}_{t}
$$

which has the same form as the one in the model with costly participation. In this model the parameter $\phi_{\lambda}$ is free - it is not pinned down because the details of wage determination are left unspecified. 


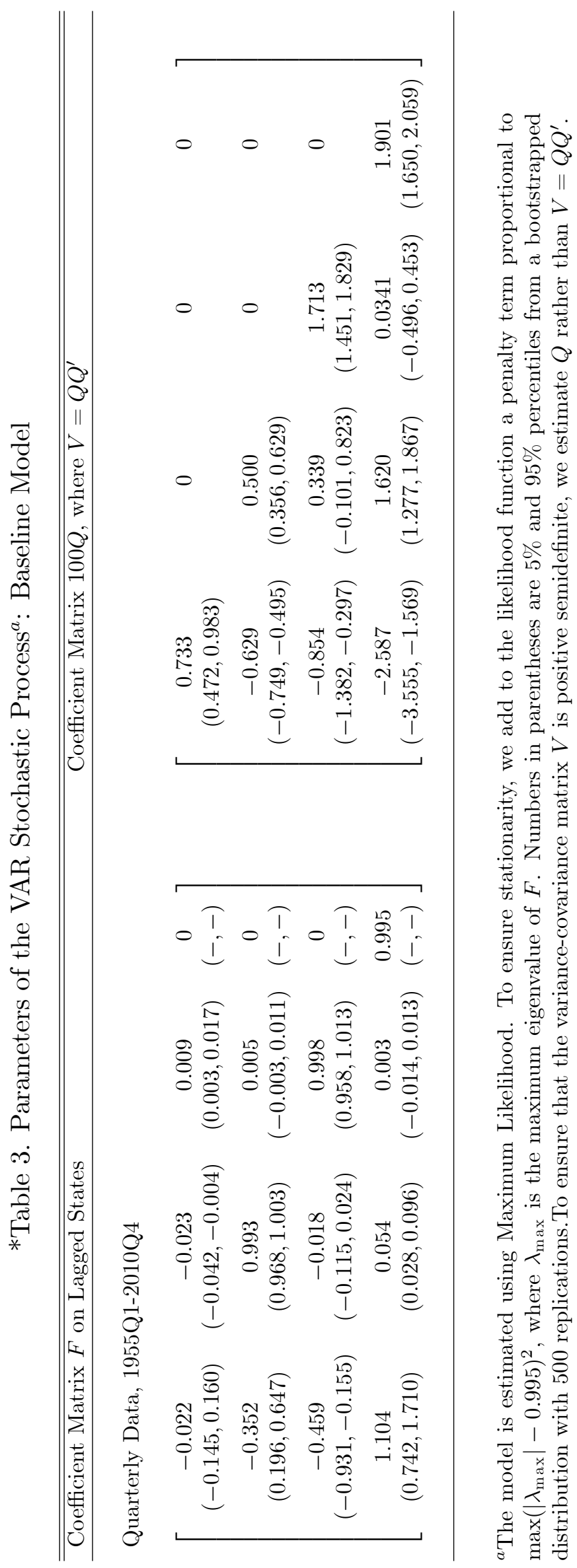

